\title{
Conceptual Design Report for the XE-6/7/8 Experiment in the NE Flux Trap
}

Joe Palmer

James Sterbentz

Paul Murray

June 2018
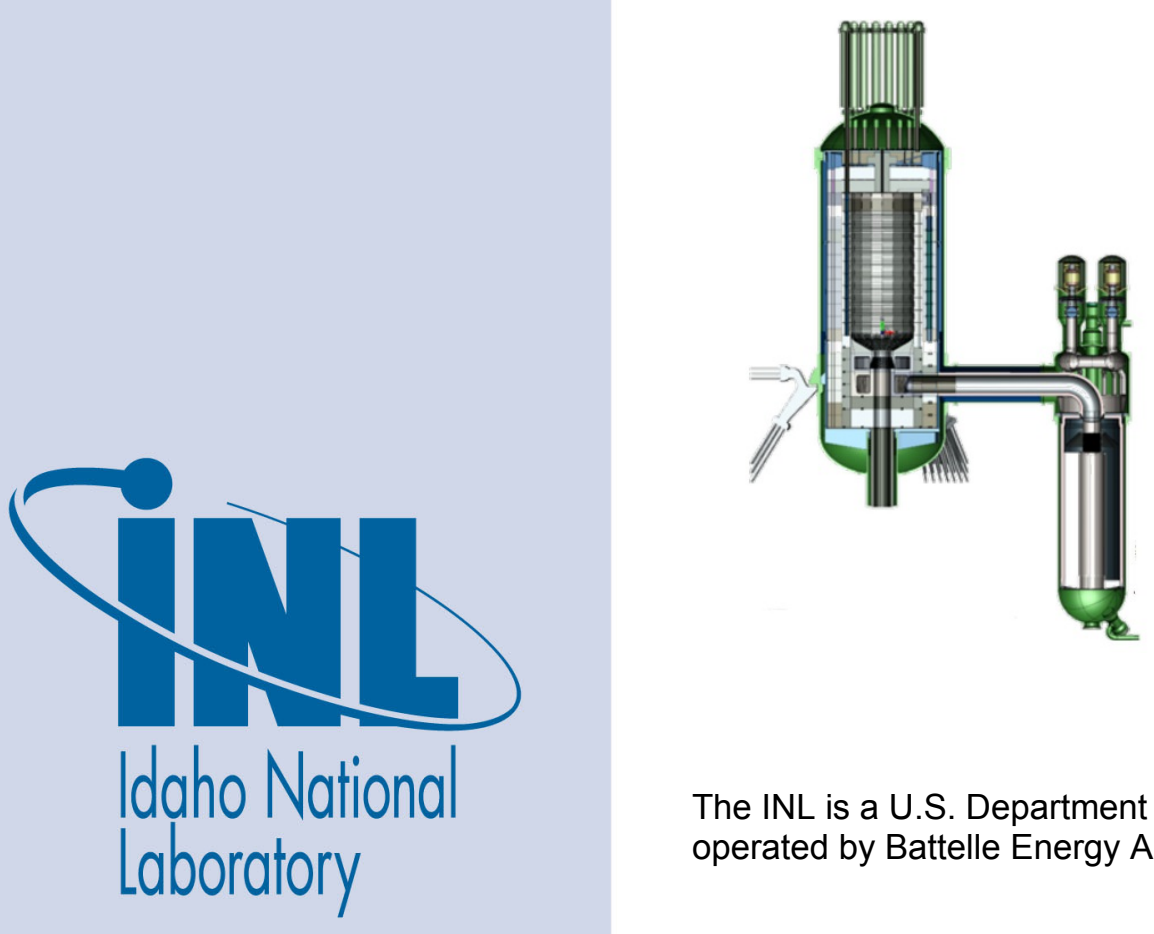

The INL is a U.S. Department of Energy National Laboratory operated by Battelle Energy Alliance 


\section{DISCLAIMER}

This information was prepared as an account of work sponsored by an agency of the U.S. Government. Neither the U.S. Government nor any agency thereof, nor any of their employees, makes any warranty, expressed or implied, or assumes any legal liability or responsibility for the accuracy, completeness, or usefulness, of any information, apparatus, product, or process disclosed, or represents that its use would not infringe privately owned rights. References herein to any specific commercial product, process, or service by trade name, trade mark, manufacturer, or otherwise, does not necessarily constitute or imply its endorsement, recommendation, or favoring by the U.S. Government or any agency thereof. The views and opinions of authors expressed herein do not necessarily state or reflect those of the U.S. Government or any agency thereof. 
INL/MIS-18-45365

\title{
Conceptual Design Report for the XE-6/7/8 Experiment in the NE Flux Trap
}

\author{
Joe Palmer \\ James Sterbentz \\ Paul Murray
}

June 2018

\section{Idaho National Laboratory \\ Idaho Falls, ID 83415}

\section{http://www.inl.gov}

Prepared for X-energy, LLC, on behalf of the

U.S. Department of Energy

Under DOE Idaho Operations Office

Contract DE-AC07-05ID14517 



\section{Conceptual Design Report for the XE-6/7/8 Experiment in the NE Flux Trap}

INL/MIS-18-45365

June 2018

Approved by:

See eCR 661162

Joe Palmer

Date

Design Engineer/Lead Author

See eCR 661162

Michael E. Davenport

Date

Experiment Manager/Checker

See eCR 661162

Paul A. Demkowicz

Date

Advanced Reactor Technologies Fuel Programs Director

See eCR 661162

Michelle T. Sharp

INL Quality Engineer 


\begin{abstract}
X-energy, LLC, has initiated conceptual design of a high-temperature, pebble-bed reactor, and requested that Idaho National Laboratory (INL) prepare a conceptual design for irradiating several fuel pebbles in the Advanced Test Reactor (ATR). The proposed fuel for the X-energy reactor utilizes tristructuralisotropic-coated fuel particles of the same specifications as those used in the U.S. Department of Energy-sponsored Advanced Gas Reactor (AGR) fuel tests, which have been irradiated in the ATR since 2006. The X-energy test has been denoted XE-6/7/8 based on nomenclature from the AGR fuel-test series. Three tests will be combined into one test train: XE- 6 constitutes the fuel qualification test, whose aim is to demonstrate fuel performance at the upper end of prototypical reactor conditions; XE-7 is designated a "margin test" and is expected to demonstrate fuel integrity at conditions substantially beyond reactor operating conditions; and XE-8 incorporates designed-to-fail particles in order to release fission products and help validate fission product release codes. The XE series of experiments would consist of multiple separate capsules that would be irradiated simultaneously. Each capsule would have its own inert sweep-gas atmosphere with individual on-line temperature monitoring. The sweep-gas effluent from each capsule would also have online fission product monitoring to track performance of the fuel in each individual capsule during irradiation. INL proposes a design consisting of six capsules, with four capsules housing a single pebble and two with double pebbles for a total of eight pebbles in the test train. The test train diameter is $9.55 \mathrm{~cm}$, while the overall length is about $109 \mathrm{~cm}$. A replaceable external neutron filter would be used to tailor the neutron flux. Instrumentation for the XE-6/7/8 test would be similar to the AGR-5/6/7 test, consisting of approximately seven $1.5 \mathrm{~mm}$ thermocouples per capsule and four fluence wires external to the capsule.

The scoping physics and thermal analyses performed for this study indicate that the experiment goals can likely be met in approximately 450 days of irradiation (similar to AGR-5/6/7). Depending on the final design configuration and refinements of the requirements, it may be possible to shorten the irradiation period by one ATR irradiation cycle.
\end{abstract}




\section{CONTENTS}

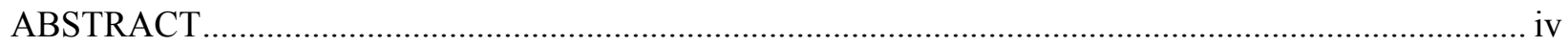

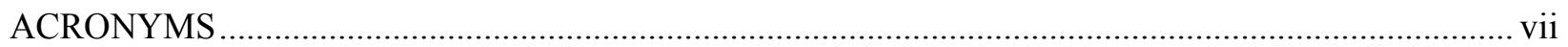

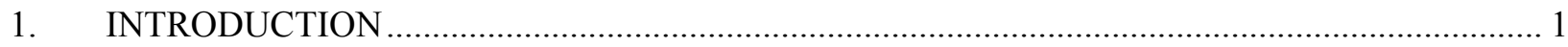

2. SCOPE

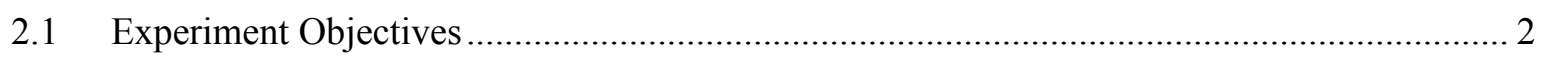

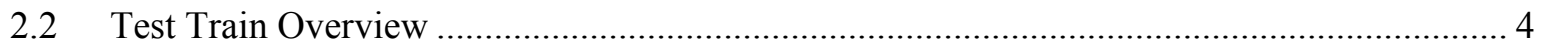

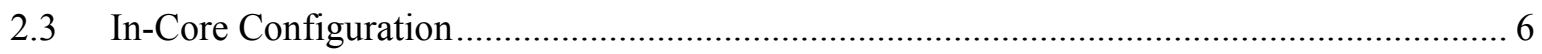

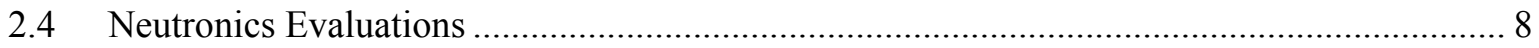

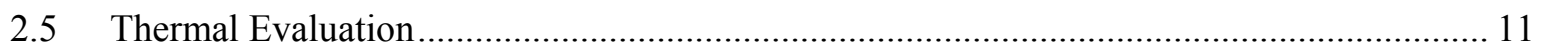

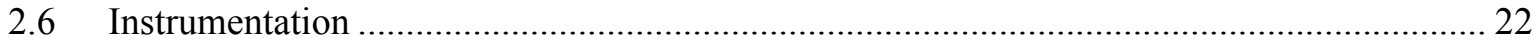

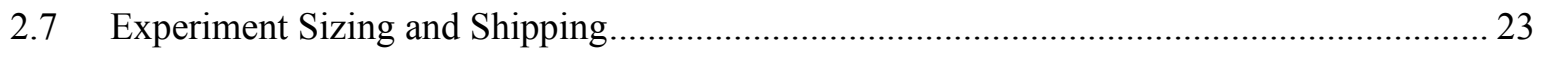

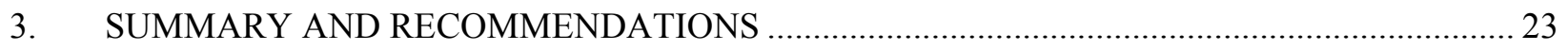

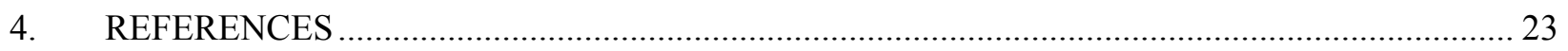

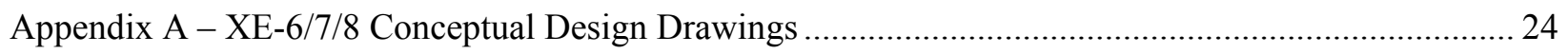




\section{FIGURES}

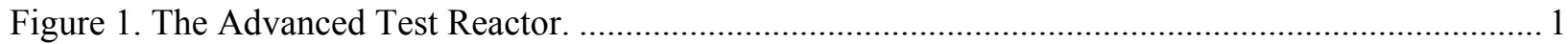

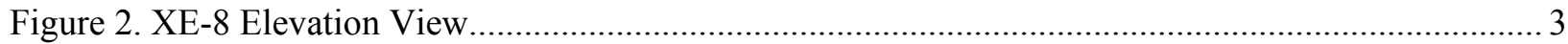

Figure 3. ATR cross section showing the proposed location of the XE-6/7/8 test. .................................. 5

Figure 4. Elevation view of XE-6/7/8 test train in the ATR vessel (left) and the complete test train

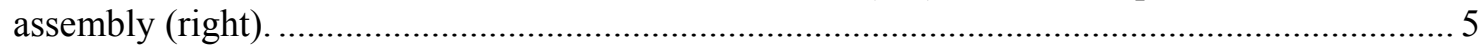

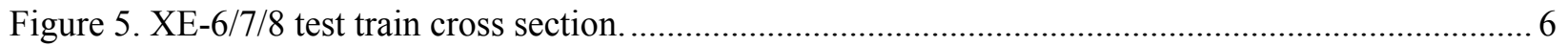

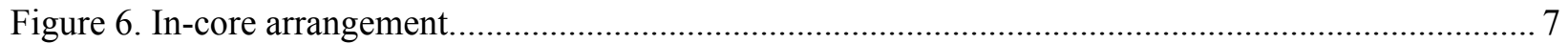

Figure 7. End-of-cycle average pebble burnup (\% FIMA) versus the ATR power cycle.........................9

Figure 8. End-of-cycle average pebble fast fluence $\left(\mathrm{E}_{\mathrm{n}}>0.18 \mathrm{MeV}\right)$ versus ATR power cycle. ............... 10

Figure 9. Model geometry and finite element mesh in a cutaway view of an experiment capsule............. 12

Figure 10. Temperature $\left({ }^{\circ} \mathrm{C}\right)$ of experiment capsules in cycle 1 in a cutaway view................................ 13

Figure 11. Temperature $\left({ }^{\circ} \mathrm{C}\right)$ of capsule 3 using the flat head design, shown in a cutaway view............... 14

Figure 12. Temperature $\left({ }^{\circ} \mathrm{C}\right)$ of capsule 3 using the modified head design, shown in a cutaway

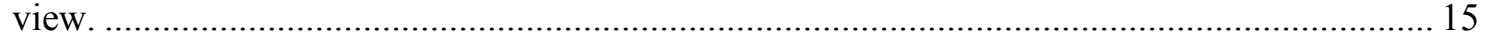

Figure 13. Temperature $\left({ }^{\circ} \mathrm{C}\right)$ of experiment capsule 3 at the proposed location of a thru-tube,

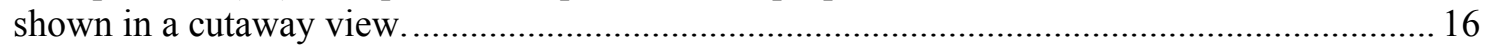

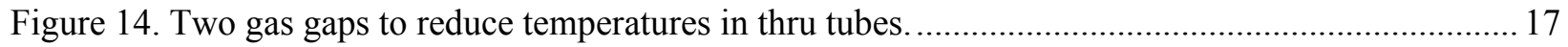

Figure 15. Fraction of fuel particles in each temperature range of XE-6 ............................................. 18

Figure 16. Fraction of fuel particles in each temperature range of XE-7 ............................................... 19

Figure 17. Fraction of fuel particles in each temperature range of XE-8 ..............................................20

Figure 18. Fraction of helium in temperature control gas in XE-6/7/8 .............................................. 21

\section{TABLES}

Table 1. Burnup and Fast Fluence Goals for XE-6/7/8 ...................................................................... 2

Table 2. Fuel Particle Temperature Distribution................................................................................... 2

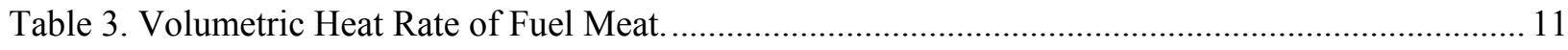

Table 4. Diameter (cm) of Graphite Holders. ....................................................................................... 22 


\section{ACRONYMS}

AGR Advanced Gas Reactor

ATR Advanced Test Reactor

DTF designed to fail

FIMA fissions per initial metal atom

FOR Functional and Operational Requirements

INL Idaho National Laboratory

PIE post irradiation examination

TRISO tristructural isotropic

TA time averaged 


\section{Conceptual Design Report for the XE-6/7/8 Experiment in the NE Flux Trap 1. INTRODUCTION}

$\mathrm{X}$-energy, LLC, is currently working toward a conceptual design for a high-temperature, pebble-bed reactor, and requested that Idaho National Laboratory (INL) prepare a conceptual design for irradiating several fuel pebbles in the Advanced Test Reactor (ATR) (see Figure 1). This report documents the conceptual design.

The proposed X-energy reactor uses tristructural isotropic (TRISO)-coated fuel particles of the same specifications as those used in the U.S. Department of Energy-sponsored Advanced Gas Reactor (AGR) fuel tests, which have been run in the ATR since 2006. The AGR-5/6/7 test is the final test in the series and began irradiation in February 2018. Many features of the AGR-5/6/7 experiment were incorporated into this conceptual design. The X-energy test has been denoted XE-6/7/8 based on nomenclature from the AGR fuel test series. As the name suggests, three basic test objectives will be combined into one test train: XE-6 constitutes the fuel qualification test, whose aim is to demonstrate fuel performance at the upper end of prototypical reactor conditions; XE-7 is designated a "margin test" and its purpose is to demonstrate fuel integrity at conditions substantially beyond reactor operating conditions; and XE-8 incorporates designed-to-fail (DTF) particles in order to release fission products and help validate fission product transport codes. The XE series of experiments would consist of multiple separate capsules that would be irradiated simultaneously. Each capsule would have its own inert sweep-gas atmosphere with individual on-line temperature monitoring. The sweep-gas effluent from each capsule would also have online fission product monitoring to track performance of the fuel in each individual capsule during irradiation. Similar to the AGR-5/6/7 test train, the XE-6/7/8 test will be irradiated in the ATR northeast flux trap irradiation position.

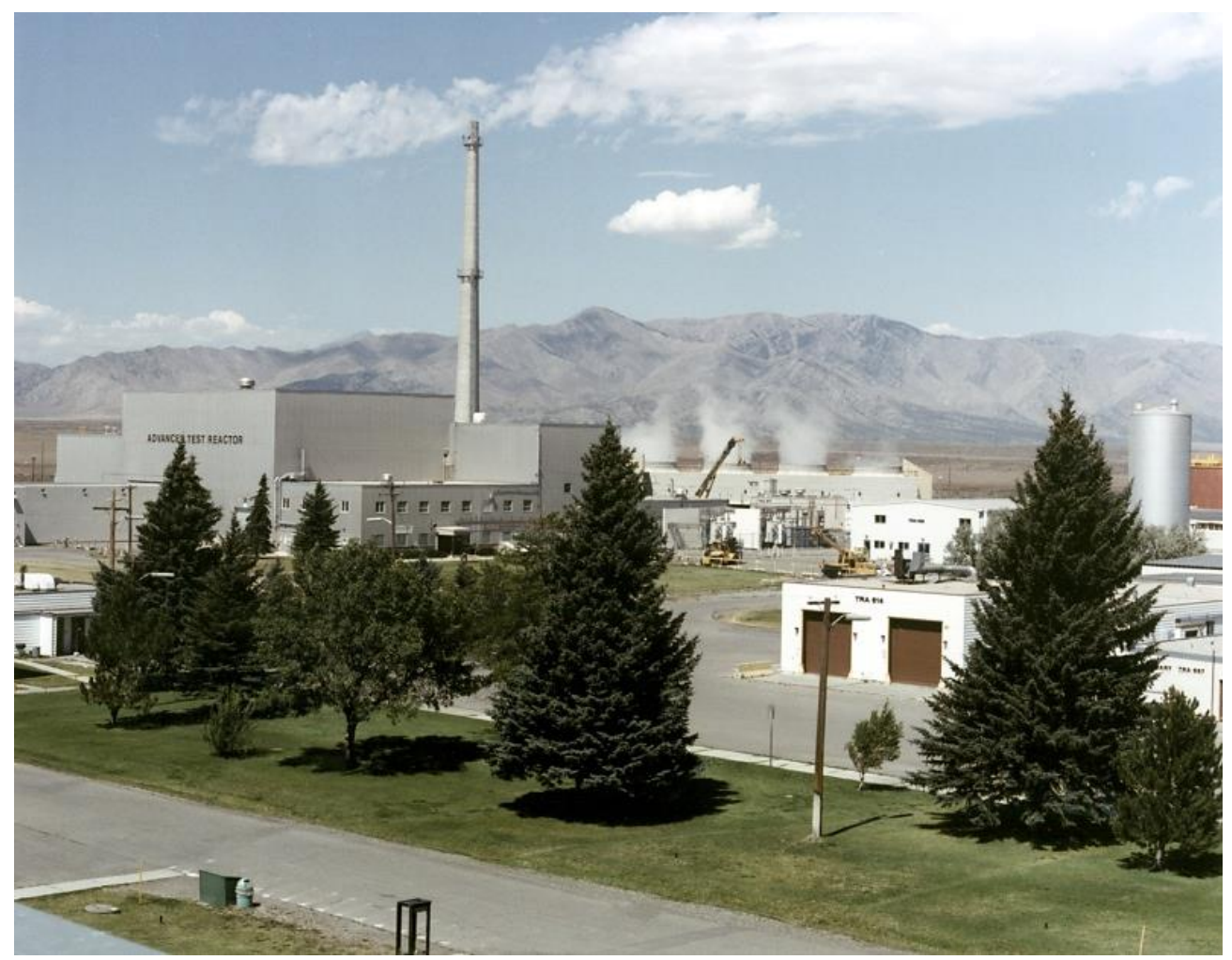

Figure 1. The Advanced Test Reactor. 


\section{SCOPE}

The XE-6/7/8 irradiation experiment will be configured as an instrumented lead, which requires extensive support equipment external to the reactor vessel. However, this conceptual design covers only the in-tank assembly (also known as the test train). It is expected that the AGR-5/6/7 support equipment outside of the reactor vessel will be available for use by the XE-6/7/8 experiment. Conceptual level neutronic and thermal analyses were performed to support preparation of the mechanical design concept and the discussion herein. The analyses should be taken as scoping in nature. Confirmatory analyses are required prior to formal design decisions.

\subsection{Experiment Objectives and Constraints}

This conceptual design was based on the requirements established in the Functional and Operational Requirements (FOR) [1] for this experiment. A summary of these requirements is provided below:

1. Irradiate 8 spheres (pebbles). [A detailed description of the pebbles and the fuel particles themselves is provided in Section 2.5.]

2. The capsules on the ends of the test train will only contain a single sphere.

3. The XE-8 pebble shall be placed at the bottom of the test train.

4. The XE-7 pebble shall be placed at or near core mid-plane so that it receives the highest neutron flux in the test train.

5. The irradiation shall be completed in 500 full-power days or fewer.

6. Provide multiple thermocouples (six or more) per capsule to help ensure several thermocouples in each capsule survive the entire irradiation period.

7. The maximum particle power limit is $300 \mathrm{~mW}$. This is essentially a restraint on burnup rate and irradiation acceleration.

8. Burnup, fast fluence, and particle temperature distribution goals are provided in Table 1 and Table 2.

Table 1. Burnup and Fast Fluence Goals for XE-6/7/8.

\begin{tabular}{|c|c|c|}
\hline Pebble & $\begin{array}{l}\text { Burnup } \\
\left(\% \text { FIMA }{ }^{a}\right)\end{array}$ & $\begin{array}{l}\text { Fast Fluence } \\
\left(\mathbf{n} / \mathbf{c m}^{2}\right)\end{array}$ \\
\hline Center four pebbles (three XE-6 and XE-7) & $\geq 16$ & $\geq 4 \times 10^{21} \ldots \leq 7.5 \times 10^{21}$ \\
\hline Four pebbles on ends of test (three XE- 6 and XE- 8 ) & $\geq 10$ & $\geq 2 \times 10^{21}$ \\
\hline
\end{tabular}

${ }^{\text {a}}$ Fissions per Initial Metallic Atom.

Table 2. Fuel Particle Temperature Distribution.

\begin{tabular}{|l|l|}
\hline Capsules & Time Averaged (TA) Temperature Distribution $\left({ }^{\mathbf{} C}\right)$ \\
\hline \multirow{3}{*}{ XE-6 $(4$ capsules/6 pebbles) } & $500-700$ for about $20 \%$ of the fuel particles \\
\cline { 2 - 2 } & $700-900$ for about $20 \%$ of the fuel particles \\
\cline { 2 - 2 } & $900-1050$ for about $30 \%$ of the fuel particles \\
\cline { 2 - 2 } & $1050-1200$ for about $30 \%$ of the fuel particles \\
\hline XE-7 $(1$ capsule/ 1 pebble $)$ & $1100-1350$ for about $80 \%$ of the fuel particles \\
\hline XE-8 $(1$ capsule/ 1 pebble $)$ & $900-1100$ for about $80 \%$ of the fuel particles \\
\hline
\end{tabular}

Table 2 represents a goal particle distribution. It is not expected that it will be achieved exactly. 
9. The configuration of the XE-8 capsule is provided below:

The XE-8 capsule serves a similar function for X-Energy as AGR-3/4 did for the AGR program, which is to provide fission product migration data in nuclear graphite at prototypical operating temperatures. As such, the configuration of the XE- 8 capsule must be different than the others. Figure 2 provides a basic schematic of this capsule.

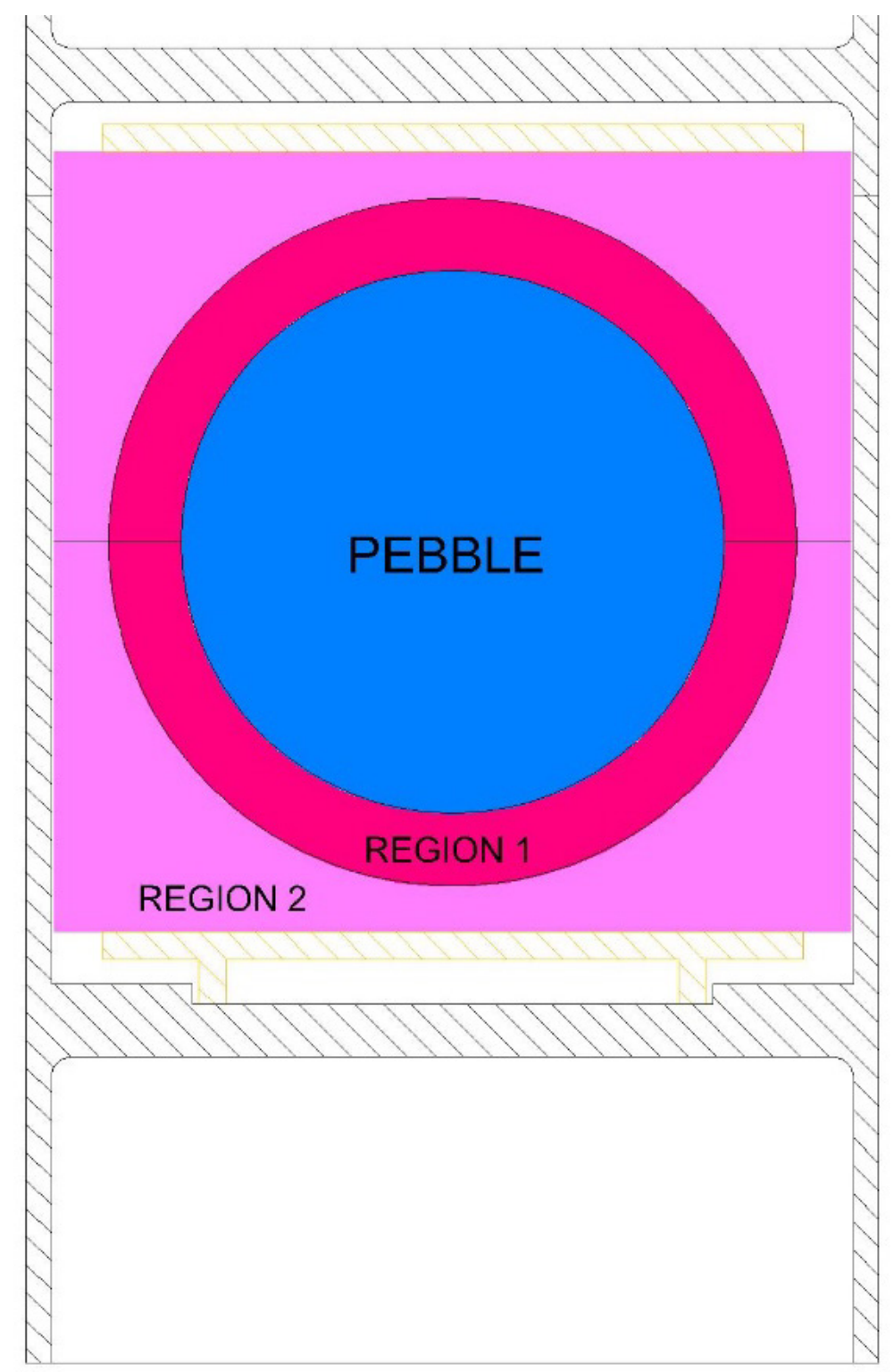

Figure 2. XE-8 Elevation View.

In this layout, a spherical graphite shell denoted as Region 1 in Figure 2, would be placed between the fuel pebble and the cylindrical cups, termed Region 2. Additionally, a small clearance gap would be incorporated between Region 1 and Region 2 to reduce the temperature in Region 2 so that it can serve as a fission product sink (similar to what was done in the AGR-3/4 experiment). This scheme is designed to provide an approximation of a 1-D transport situation. For this capsule, the temperature of interest is likely the Region 1 graphite, rather than the fuel temperature. The goal temperature of Region 1 is 
expected to be approximately $800^{\circ} \mathrm{C}+/-50^{\circ} \mathrm{C}$, while the Region 2 temperature is approximately $550^{\circ} \mathrm{C}+/-$ $50^{\circ} \mathrm{C}$.

Additional constraints (or potential constraints) were identified by the design team during this design study and are listed below:

- Controllability of the fuel temperature. Very high heat rates require small control gas gaps. As design gas gaps decrease, machining tolerances and shrinkage of the graphite holders during irradiation become more and more important, causing uncertainties in the true size of the gas gaps and great difficulty controlling temperatures. Based on the AGR series of experiments, the minimum gas gap for effective experiment temperature control is about $0.025 \mathrm{~cm}$. This constraint comes into play in determining the maximum fuel heat rate that can be tolerated.

- ATR northeast lobe power. Each of the four outer ATR lobes can be controlled somewhat independently of the others; however, there are limits to the mismatch between lobes. Based on typical ATR operating conditions, the lowest power at which the northeast lobe can be operated is $13 \mathrm{MW}$. For design purposes, the minimum lobe power is typically assumed to be $14 \mathrm{MW}$, while the maximum is typically assumed to be approximately $20 \mathrm{MW}$.

\subsection{Test Train Overview}

XE-6/7/8 will be an instrumented lead-type experiment with on-line active temperature control and fission product monitoring of the effluent gas. The overall concept for temperature control of the experiment capsules, the temperature control system design, and the fission product monitoring system design are all essentially identical to those used on AGR-3/4 and AGR-5/6/7. The experiment capsules use an insulating gas jacket with variable mixtures of helium and neon sweep gases to control fuel temperatures in each capsule during irradiation.

Instrumented lead experiments are called such because a conduit is established between the in-core portion of the experiment and the vessel boundary - in this case, the top head of the reactor. Because of the large diameter of the fuel specimens (6-cm pebbles), only one high-flux position in the ATR can accommodate the experiment - the northeast flux trap, as shown in Figure 3. There is an existing vessel penetration directly above the northeast flux trap; therefore, the lead-out would consist of straight sections of pipe passing directly upward and out of the ATR vessel, as shown in Figure 4.

The northeast flux trap is an ideal position for this type of fuel experiment because power can be varied over the duration of the test. The lobe power can be increased from 14 to $20 \mathrm{MW}$. As the fuel fissile content decreases and the heat rate drops, the lobe power can be increased to compensate; however, there is not enough adjustment to totally compensate for the heat-rate drop off, so other means are necessary, such as replaceable filters. 


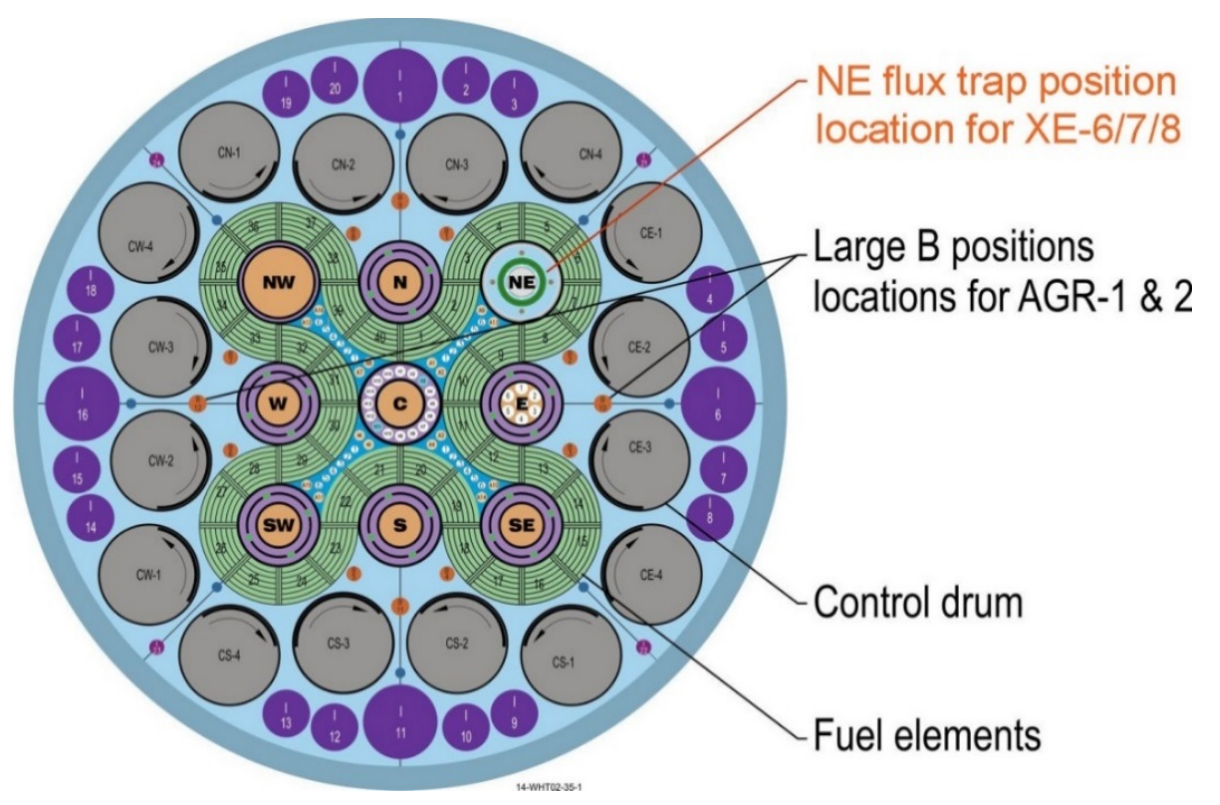

Figure 3. ATR cross section showing the proposed location of the XE-6/7/8 test.
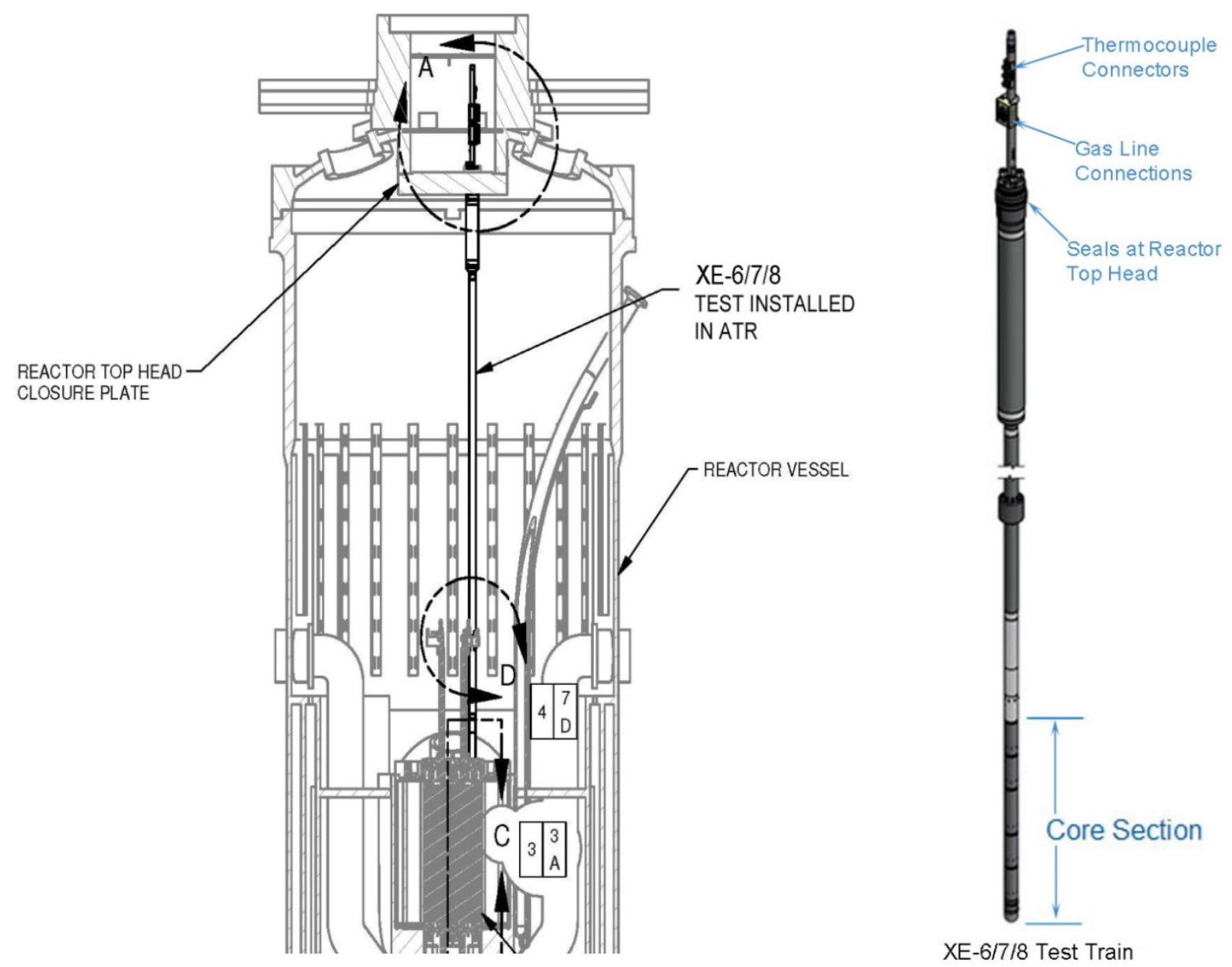

Figure 4. Elevation view of XE-6/7/8 test train in the ATR vessel (left) and the complete test train assembly (right). 


\subsection{In-Core Configuration}

Due to the large diameter of the pebbles, the XE-6/7/8 capsule diameter will be about $35 \%$ larger than AGR-5/6/7 $(9.55 \mathrm{~cm}$ versus $7.02 \mathrm{~cm})$. This larger diameter will displace considerably more water than was displaced by the AGR-3/4 or AGR-5/6/7 experiments, resulting in a harder neutron spectrum, other factors being equal.

The AGR-3/4 and AGR-5/6/7 experiments incorporated external neutron filtering, and this conceptual design incorporates an external filter similar to that used for AGR-5/6/7 as illustrated in Figure 5. The neutronics studies performed for this design indicate that very little filtering is required (or desired - so as not to harden the spectrum too much). The filter consists of simply a stainless steel sleeve. It serves the dual purpose of absorbing some thermal neutrons, and it also supports the test laterally in the flux trap.

This arrangement allows the neutron filtering to be changed (reduced) at the program's discretion as the experiment progresses. For AGR-5/6/7, two different filters have been constructed, and they can be changed to maximize fission rate while staying within a compact heat-rate range that can be accommodated by gas-blend adjustments. The same strategy is proposed for XE-6/7/8 (i.e., it appears that two filters would be sufficient to provide the adjustment necessary to compensate for fuel burnup). The filters for XE-6/7/8 would not incorporate any hafnium, but rather be simply solid stainless steel cylinders of two thicknesses. For the early irradiation cycles, the filter would be $0.45 \mathrm{~cm}$ in the middle section and reduced to $0.32 \mathrm{~cm}$ on the ends. For the later irradiation cycles, the filter would be $0.32 \mathrm{~cm}$ throughout its length. This strategy will have the effect of increasing the burnup on the capsules at the top and bottom relative to the capsules near core mid-plane. See Section 2.4 for further details of the changeout schedule of the two filters.

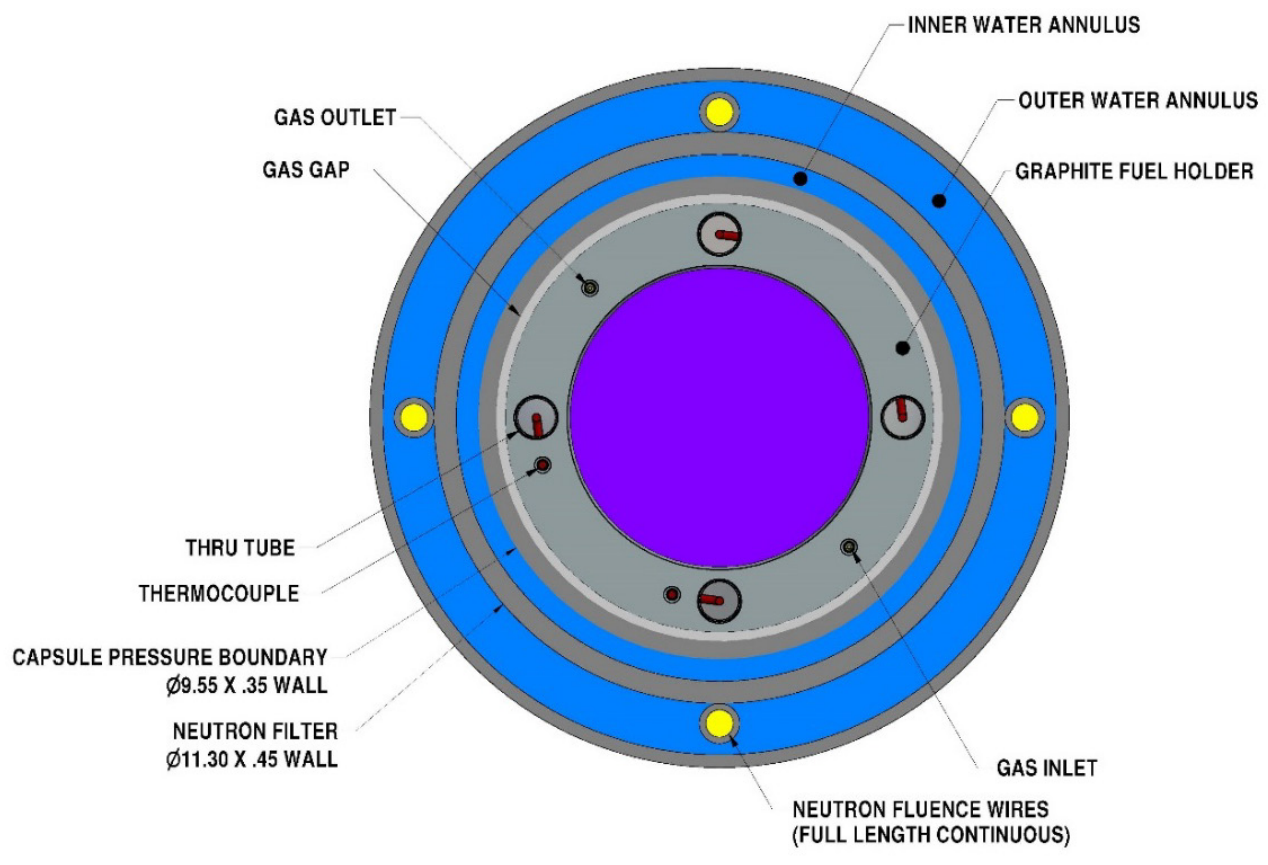

Figure 5. XE-6/7/8 test train cross section.

An elevation cross-section of the in-core portion of the test is shown in Figure 6. There are six separate capsules, with four housing a single pebble and two with double pebbles, for a total of eight pebbles in the test train. In this concept, the test train covers the center $98.8 \mathrm{~cm}$ of the $122-\mathrm{cm}$-tall core. Staying away from the edges of the core reduces flux gradients on the end capsules. The XE-7 capsule is placed just below core mid-plane, which is the highest flux position. The ATR flux is slightly asymmetric, with the highest flux being just below core mid-plane. 


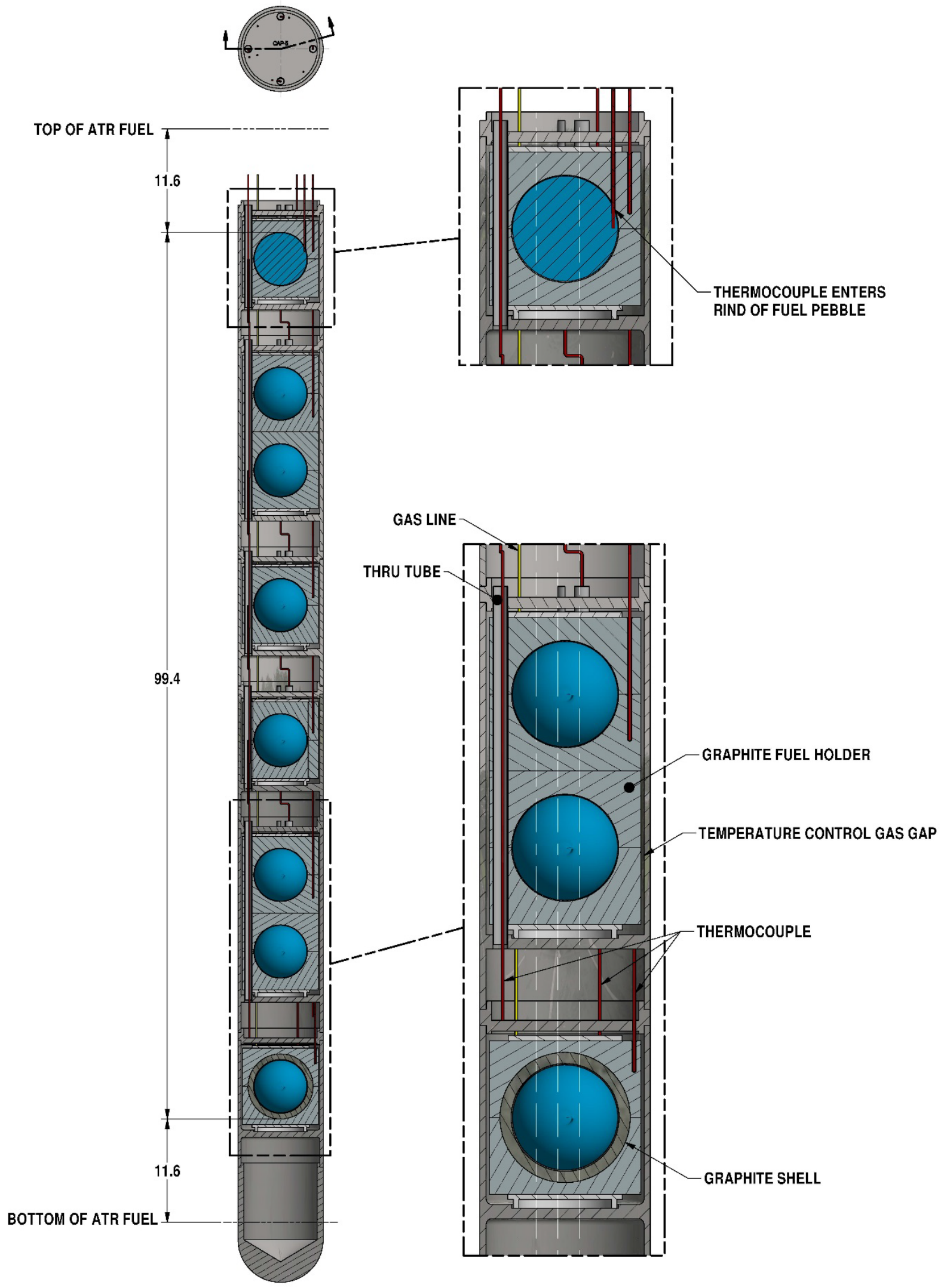

Figure 6. In-core arrangement. 
The XE-8 pebble is slated to contain DTF fuel and is placed in the bottom capsule where there are no thru-tubes. This was deemed the best location because thru-tubes tend to break up the symmetry and might create difficulties in measuring the fission product concentrations in the graphite holders. As shown in Figure 6, this bottom capsule will incorporate a spherical graphite shell (built from two half-shells) around the pebble to capture fission products emanating from DTF particles embedded in this particular pebble.

This axial layout incorporates fairly generous plenum regions between capsules, making it easier to bend the thermocouples coming out of the capsule heads and into the thru-tubes. Putting less-severe bends in the thermocouples is thought to improve the thermocouples' survivability; however, if the plenum heights were reduced, it would allow the top and bottom pebbles to be moved a few centimeters closer to core mid-plane with a concomitant increase in neutron flux for these outboard capsules.

\subsection{Neutronics Evaluations}

Scoping physics calculations were performed based on the conceptual test train design presented in previous sections of this report. Each pebble was modeled with an outer diameter of $6.0 \mathrm{~cm}$. The spherical pebbles have a central fuel meat surrounded by a graphite rind. The $5.0-\mathrm{cm}$-diameter fuel meat contains TRISO particles embedded in a graphite matrix. The rind is made up of an all graphite matrix with a 0.5-cm thickness.

The TRISO particle design and enrichment are identical to the particle design used in the AGR-5/6/7 irradiation test. The uranium in the 425- $\mu \mathrm{m}$ UCO kernel is enriched to $15.5 \mathrm{wt} \% \mathrm{U}-235$. The fuel meat volume $\left(65.45 \mathrm{~cm}^{3}\right)$ is assumed to contain 18,000 TRISO particles to give a particle packing fraction of approximately $9.15 \%$. Each pebble then contains $1.12 \mathrm{~g} \mathrm{U}-235,6.08 \mathrm{~g} \mathrm{U}-238$, and $7.22 \mathrm{~g} \mathrm{U}$ total. In the Monte Carlo N-Particle model, the fuel meat was homogenized for simplicity.

The physics calculations were performed for nine 50-day cycles for a total of 450 days of irradiation. The northeast lobe power was gradually increased from $14 \mathrm{MW}$ to $20 \mathrm{MW}$. For the first eight cycles, the stepped $0.45-\mathrm{cm}$-thick filter described in Section 2.3 was used. The constant thickness 0.32 -cm-thick filter was used only for the final cycle. As the design matures, it is likely that the thinner filter will be scheduled to be put into service earlier, which will increase the burnup rate and reduce the total fast fluence accumulation.

Figure 7 shows the cycle-by-cycle burnup accumulation for each pebble given the lobe powers, as shown in the upper right-hand corner. The pebble locations are denoted by the eight node marks on each of the curves. As illustrated in the figure, the four center pebbles achieve the goal of 16\% FIMA by the end of the ninth cycle, or at approximately 450 days of irradiation. This goal could possibly be achieved up to one full cycle earlier by deploying the light filter at perhaps as early as the sixth cycle. 


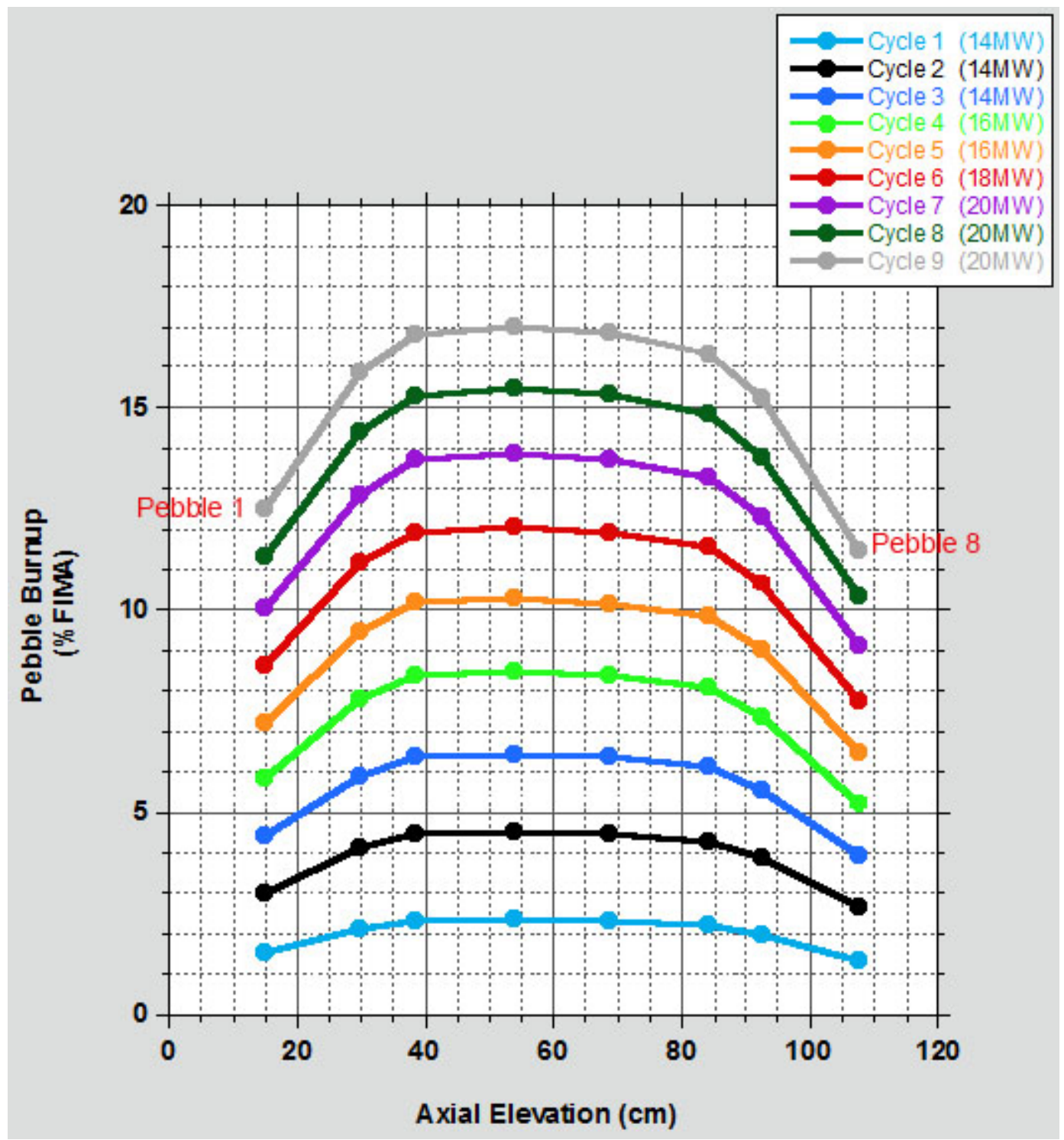

Figure 7. End-of-cycle average pebble burnup (\% FIMA) versus the ATR power cycle.

Figure 8 shows the cycle-by-cycle fast fluence accumulation for each pebble given the lobe powers, as shown in the upper right-hand corner. All pebbles reach the minimum fast fluence goals provided in Table 1 at the end of 450 days of irradiation. However, pebble 4 slightly exceeds the $7.5 \times 10^{21} \mathrm{n} / \mathrm{cm}^{2}$-sec fast fluence limit given in Table 1. This problem could be overcome by employing the light filter earlier, which would have the effect of softening the spectrum and allow for reaching the 16\% FIMA goal prior to hitting the fast fluence limit. 


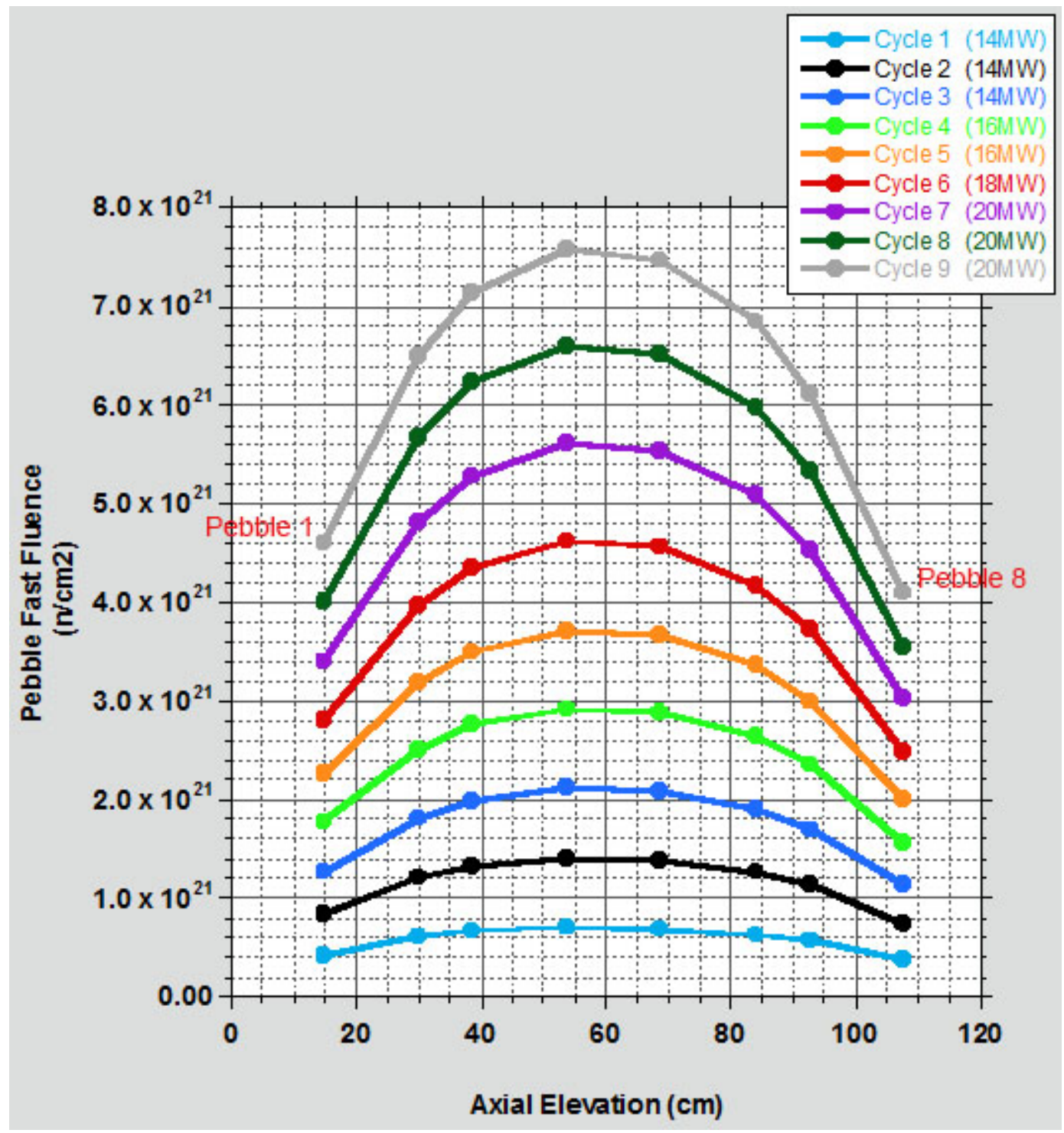

Figure 8. End-of-cycle average pebble fast fluence $\left(E_{n}>0.18 \mathrm{MeV}\right)$ versus ATR power cycle.

Calculated volumetric heat rates for each pebble for cycles 1, 5, and 9 are provided in Table 3 . Note that these heat rates are reasonably constant for each pebble over the three cycles, indicating that the strategy of increasing power and changing filters produces a fairly flat power profile, which is a great aid in maintaining constant temperature throughout the irradiation period. The maximum volumetric heat rate of $53 \mathrm{~W} / \mathrm{cc}$ occurs in Pebble 4 in the first cycle. The corresponding particle power for this heat rate is $194 \mathrm{~mW}$, which is nearly identical to the peak particle power in AGR-5/6/7, and is comfortably under the established $300 \mathrm{~mW}$ peak particle power limit. 
Table 3. Volumetric Heat Rate of Fuel Meat.

\begin{tabular}{|c|c|c|c|}
\hline Pebble & $\begin{array}{c}\text { Cycle 1 } \\
\text { 14 MW Lobe Power } \\
\text { (W/cc) }\end{array}$ & $\begin{array}{c}\text { Cycle 5 } \\
\text { 16 MW Lobe Power } \\
\text { (W/cc) }\end{array}$ & $\begin{array}{c}\text { Cycle 9 } \\
\text { 20 MW Lobe Power } \\
\text { (W/cc) }\end{array}$ \\
\hline 1 & 34.4 & 31.8 & 30.2 \\
\hline 2 & 46.9 & 41.1 & 40.2 \\
\hline 3 & 52.2 & 44.3 & 42.5 \\
\hline 4 & 53.0 & 44.7 & 44.1 \\
\hline 5 & 52.7 & 44.7 & 43.7 \\
\hline 6 & 49.8 & 42.9 & 42.0 \\
\hline 7 & 44.5 & 39.8 & 39.7 \\
\hline 8 & 30.3 & 29.1 & 29.0 \\
\hline
\end{tabular}

\subsection{Thermal Evaluation}

Scoping thermal calculations were performed to verify that the desired temperature distributions can be achieved by means of reasonably sized temperature control gas gaps (e.g., $0.025-0.15 \mathrm{~cm}$ ). A coupled temperature-displacement analysis was performed in order to account for heat generation, thermal expansion, and irradiation-induced shrinkage of graphite. The effect of the helium-neon gas mixture on the gas gap conductance and the effect of neutron fluence on the thermal conductivity and shrinkage of the graphite was included in the analysis. The results of the analysis were used to determine the gas gaps and gas mixtures needed to attain the desired temperature distribution in the pebbles.

The thermal analysis was performed at three irradiation cycles (i.e., the first, fifth, and ninth cycles) to encompass the anticipated conditions of reactor power and neutron fluence occurring during irradiation. The heat generation rates used in the analysis were obtained from a separate reactor physics analysis described in the previous section. The ATR northeast lobe power was assumed to be $14 \mathrm{MW}$ in cycle 1, $16 \mathrm{MW}$ in cycle 5, and $20 \mathrm{MW}$ in cycle 9 in order to compensate for diminishing heat generation due to fuel burnup.

The desired temperature distribution in the pebbles, given in terms of the desired fraction of fuel particles in each temperature range, is provided in Table 2.

The experiment consists of 6 capsules, each of which is designed to contribute fuel particles in a particular temperature range. XE-6 consists of capsules 2, 4, 5, and 6; XE-7 consists of capsule 3; and XE- 8 consists of capsule 1. Capsules 2 and 5 contain two pebbles, while all other capsules contain one pebble.

A finite element temperature-displacement analysis of the XE-6/7/8 experiment was performed using ABAQUS. A cutaway view of the model geometry and finite element mesh of one of the experiment capsules is shown in Figure 9. In this figure, the capsule is blue, the holder is green, the pebble is red, and the zirconia insulators are orange. The neutron filter and primary coolant are not shown. A cutaway view of the temperature distribution throughout the entire in-core test train at the middle of the first cycle is shown in Figure 10. 


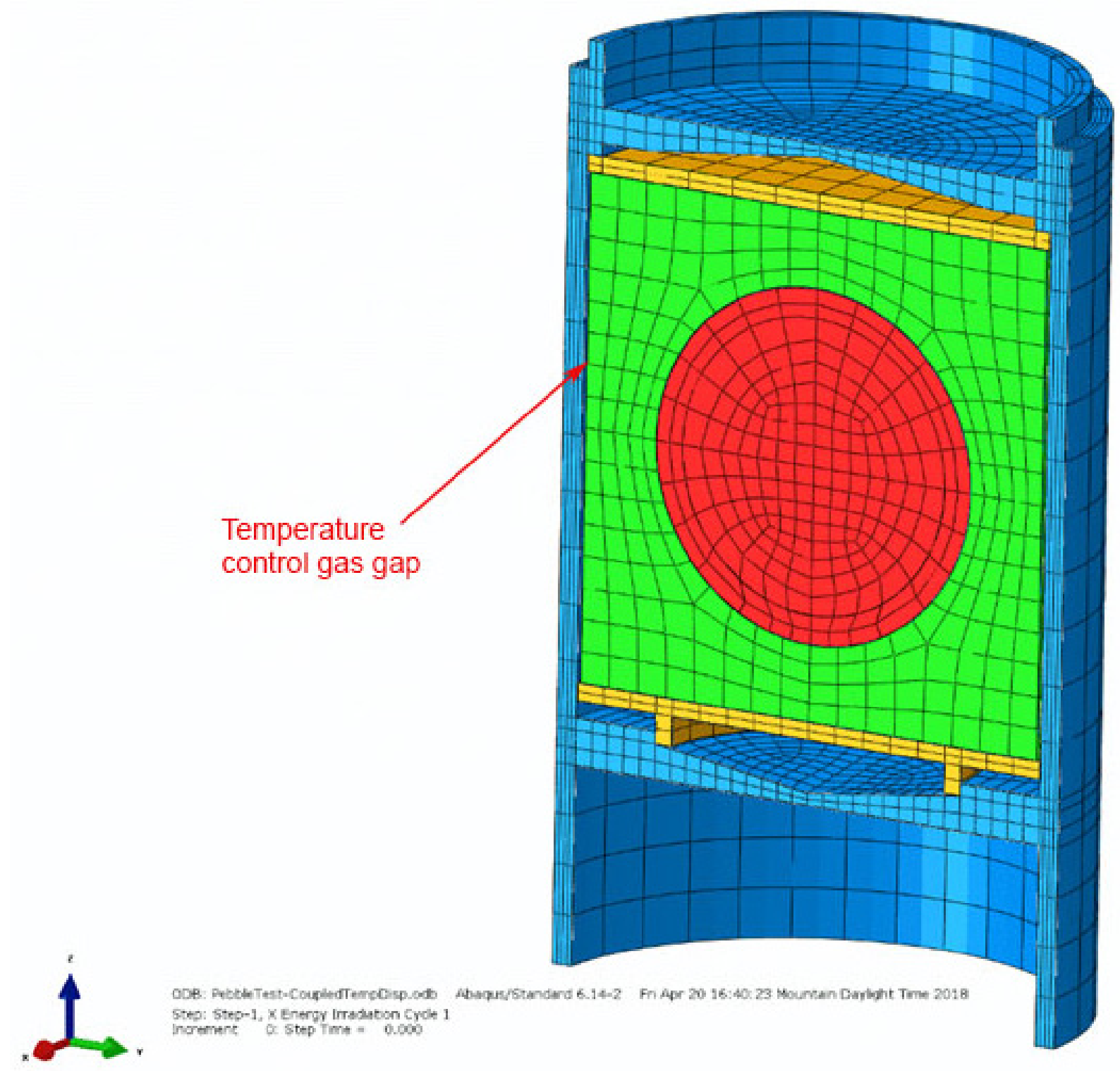

Figure 9. Model geometry and finite element mesh in a cutaway view of an experiment capsule. 


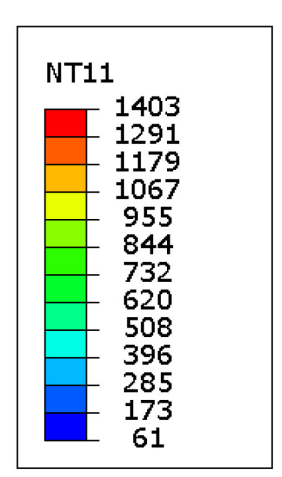

XE-6/7/8 Experiment Temperature (deg C)

at the middle of the first irradiation cycle

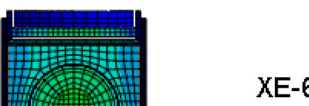

XE-6
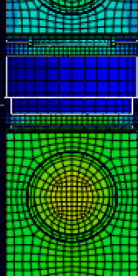

$\mathrm{XE}-6$
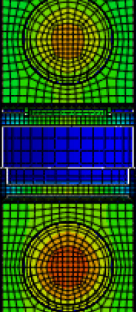

$\mathrm{XE}-6$
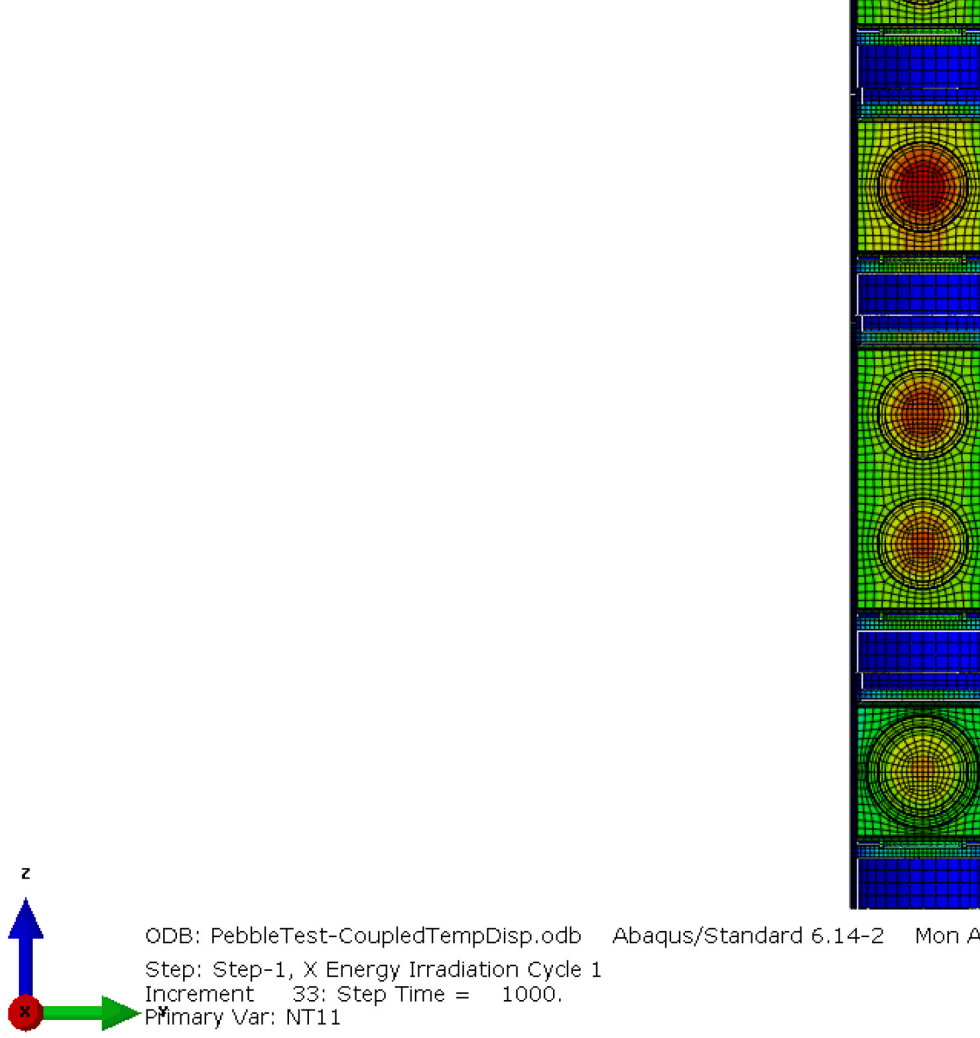

ODB: PebbleTest-CoupledTempDisp.odb

Step: Step-1, X Energy Irradiation Cycle

Increment 33: Step Time $=1000$.

Pimary Var: NT11

Figure 10. Temperature $\left({ }^{\circ} \mathrm{C}\right)$ of experiment capsules in cycle 1 in a cutaway view.

A closer examination of the finite element analysis results revealed that the temperature of the capsule top and bottom heads was too high due to gamma heating of the heads during high power cycles. The original design included stainless steel flat heads. A cutaway view of the temperature of capsule 3 during cycle 9 at $20 \mathrm{MW}$ NE lobe power using the flat head design is shown in Figure 11. The maximum temperature of the heads is $1345^{\circ} \mathrm{C}$, which is too close to the melting temperature of stainless steel $\left(1400^{\circ} \mathrm{C}\right)$. 


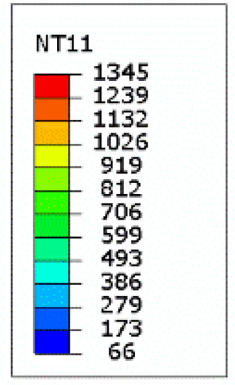

Capsule 3 (XE- 7 ) temperature (degrees C) during cycle 9 at 20 MW NE lobe power

using the capsule flat head design

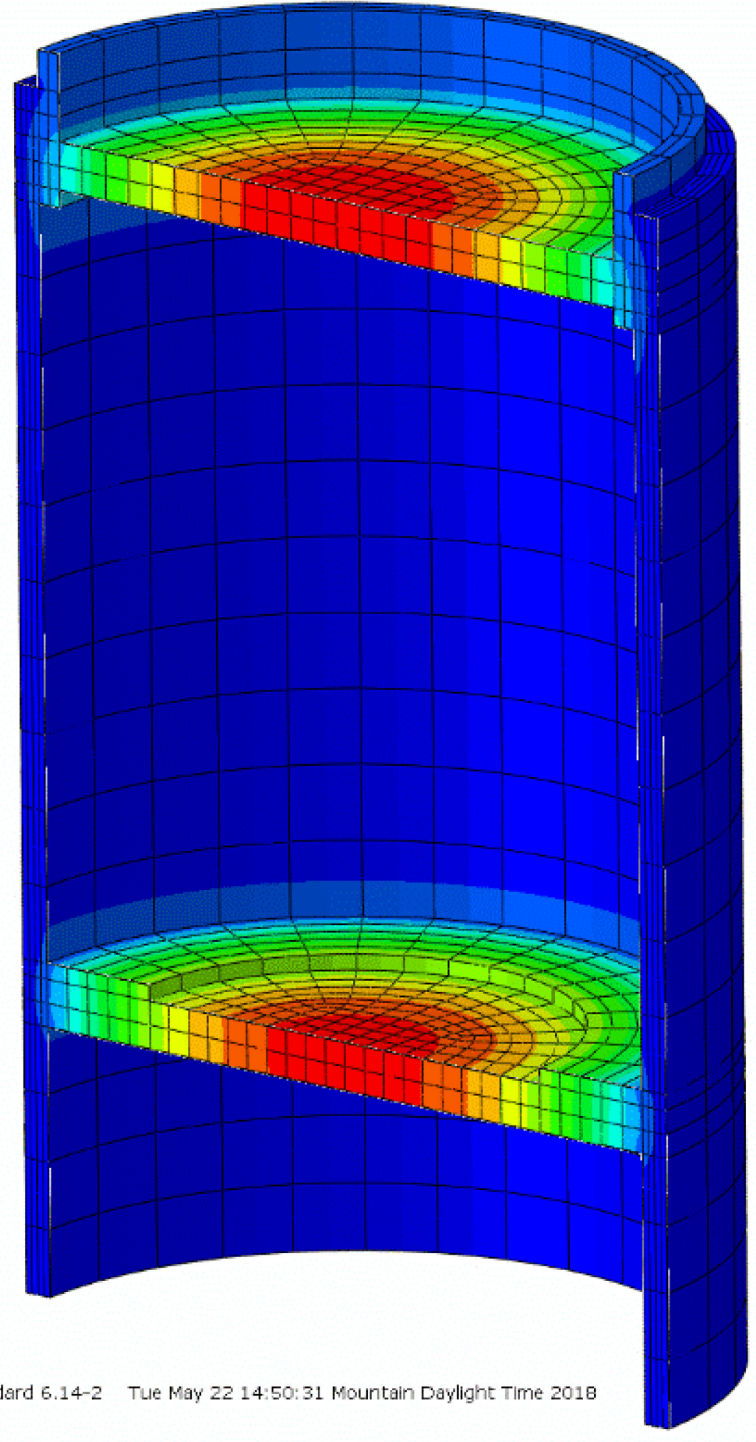

Step: Step-1, X Energy Irradiation Cycle

Increment 34 : Step Time $=$

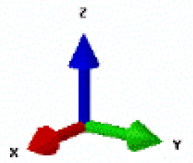

Frimary Var: NTi

Figure 11 . Temperature $\left({ }^{\circ} \mathrm{C}\right)$ of capsule 3 using the flat head design, shown in a cutaway view.

The ABAQUS model was modified to reduce the thickness at the center of the heads and replace the stainless steel with nickel in the center portion of the head. Nickel has a higher thermal conductivity and a higher melting temperature than stainless steel. A cutaway view of the temperature of capsule 3 during cycle 9 at $20 \mathrm{MW}$ NE lobe power using the modified head design is shown in Figure 12. In this case, the maximum temperature of the heads is $899^{\circ} \mathrm{C}$, so the modified design is effective in reducing the temperature to an acceptable level. However, this particular bi-metallic head design has not previously been incorporated into any INL reactor experiment; as such, some engineering and weld procedure development will need to be done as a part of the final design process. 

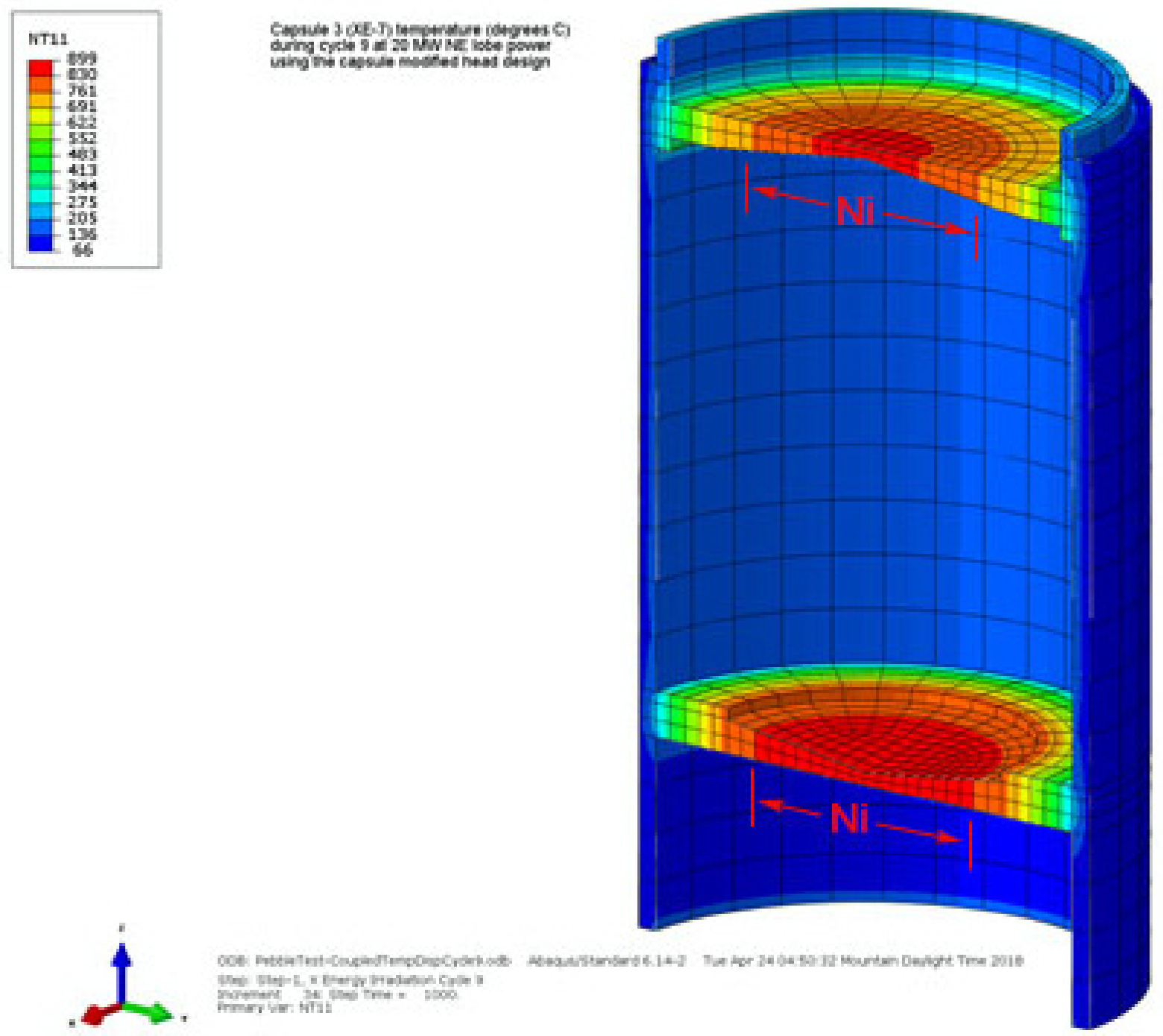

Figure 12. Temperature $\left({ }^{\circ} \mathrm{C}\right)$ of capsule 3 using the modified head design, shown in a cutaway view.

Thru-tubes containing thermocouples and gas-lines pass through the capsule and graphite holder. A cutaway view of the temperature of capsule 3 during cycle 1 at 14 MW NE lobe power is shown in Figure 13. The approximate location of a thru-tube is shown in the figure. The maximum temperature of the capsule components at the location of a thru-tube is approximately $1200^{\circ} \mathrm{C}$, which is at least $200^{\circ} \mathrm{C}$ too hot for the thermocouples passing through it. The proposed solution to this problem is to separate the graphite fuel holder into two pieces as was done for AGR-7. As shown in Figure 14, a small clearance would be established between the two layers, which will serve to reduce the temperature in the outer layer (as it did for AGR-7). 


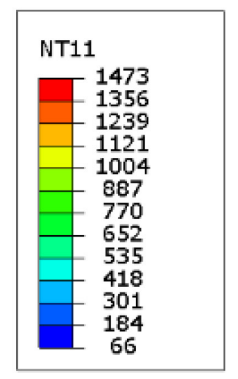

Capsule 3 (XE-7) temperature (degrees $\mathrm{C}$ ) during cycle 1 at 14 MW NE lobe power

$1200 \mathrm{C}$ maximum temperature at the location of the thru-tubes

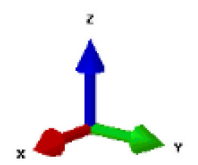

ODE: PebbleTest-CoupledTempDisp.odb Abaqus/Standard 6.14-2 Fri Apr 20 16:40:23 Mountain Daylight Time 2018 Step: Step-3, X Energy Irradiation Cycle 9

Increment $19:$ Step Time $=1000$
Frimary Var: NT11

Figure 13. Temperature $\left({ }^{\circ} \mathrm{C}\right)$ of experiment capsule 3 at the proposed location of a thru-tube, shown in a cutaway view. 


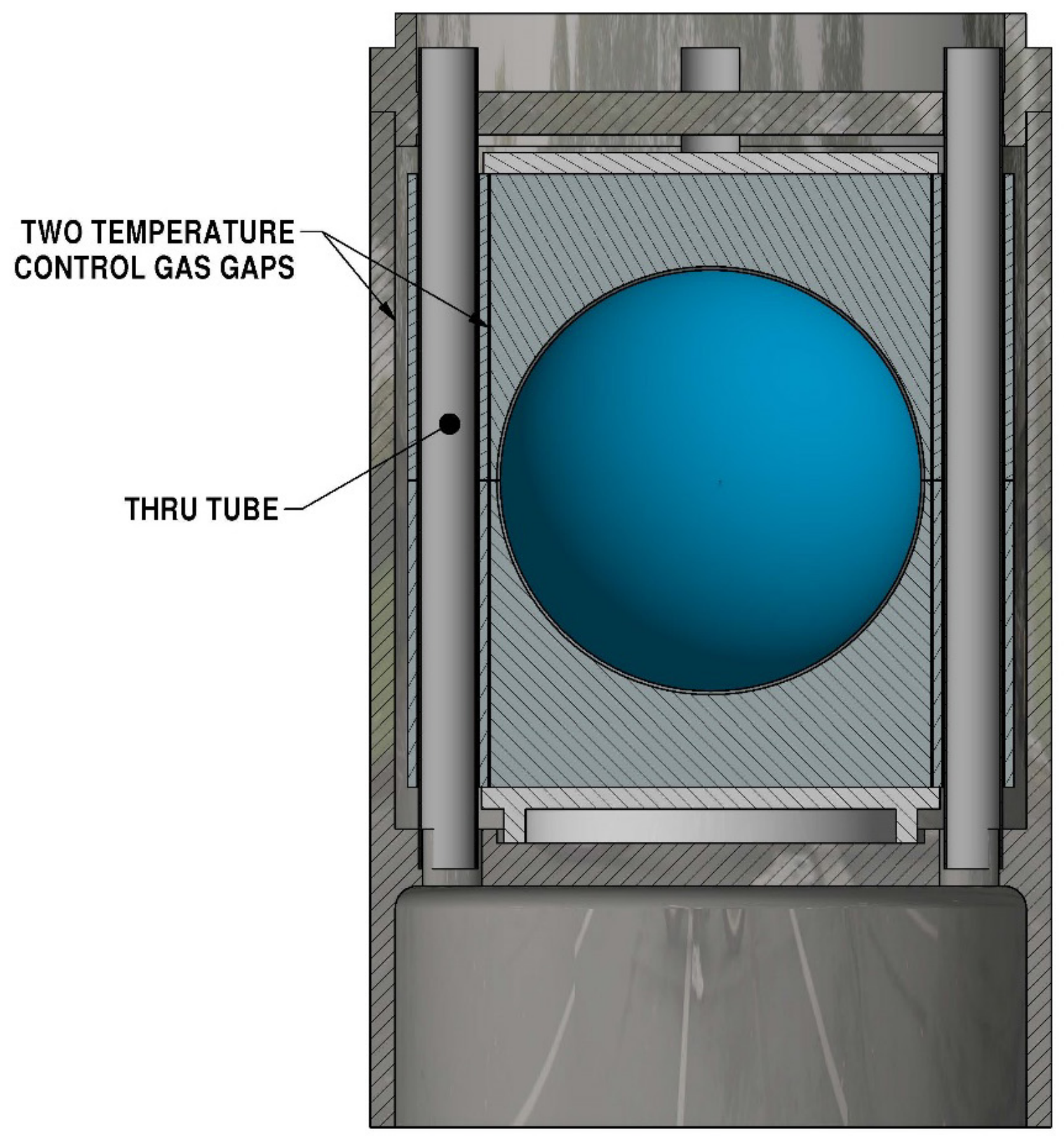

Figure 14. Two gas gaps to reduce temperatures in thru-tubes.

Graphs of the fraction of particles in each temperature range at cycles 1, 5, and 9 are shown in Figure 15 (XE-6), Figure 16 (XE-7), and Figure 17 (XE-8), respectively. A graph of the gas mixtures needed at cycles 1,5 , and 9 is shown in Figure 18. The results of this analysis indicate the gas mixtures can be adjusted to maintain desired pebble temperature distribution. The irradiation begins with using a $50 \%$ helium $/ 50 \%$ neon gas mixture in all capsules. The helium content increases during irradiation to compensate for irradiation-induced shrinkage of graphite and the reduction in thermal conductivity of graphite. Note that cycle 9 at $20 \mathrm{MW}$ lobe power may require close to $100 \%$ helium to control the pebble temperature. However, the actual gas mixtures used during irradiation may be different from those given here, due to uncertainty in the gas gaps and reactor power. Additional adjustments available during irradiation include the lobe power and the thickness of the neutron filter. 


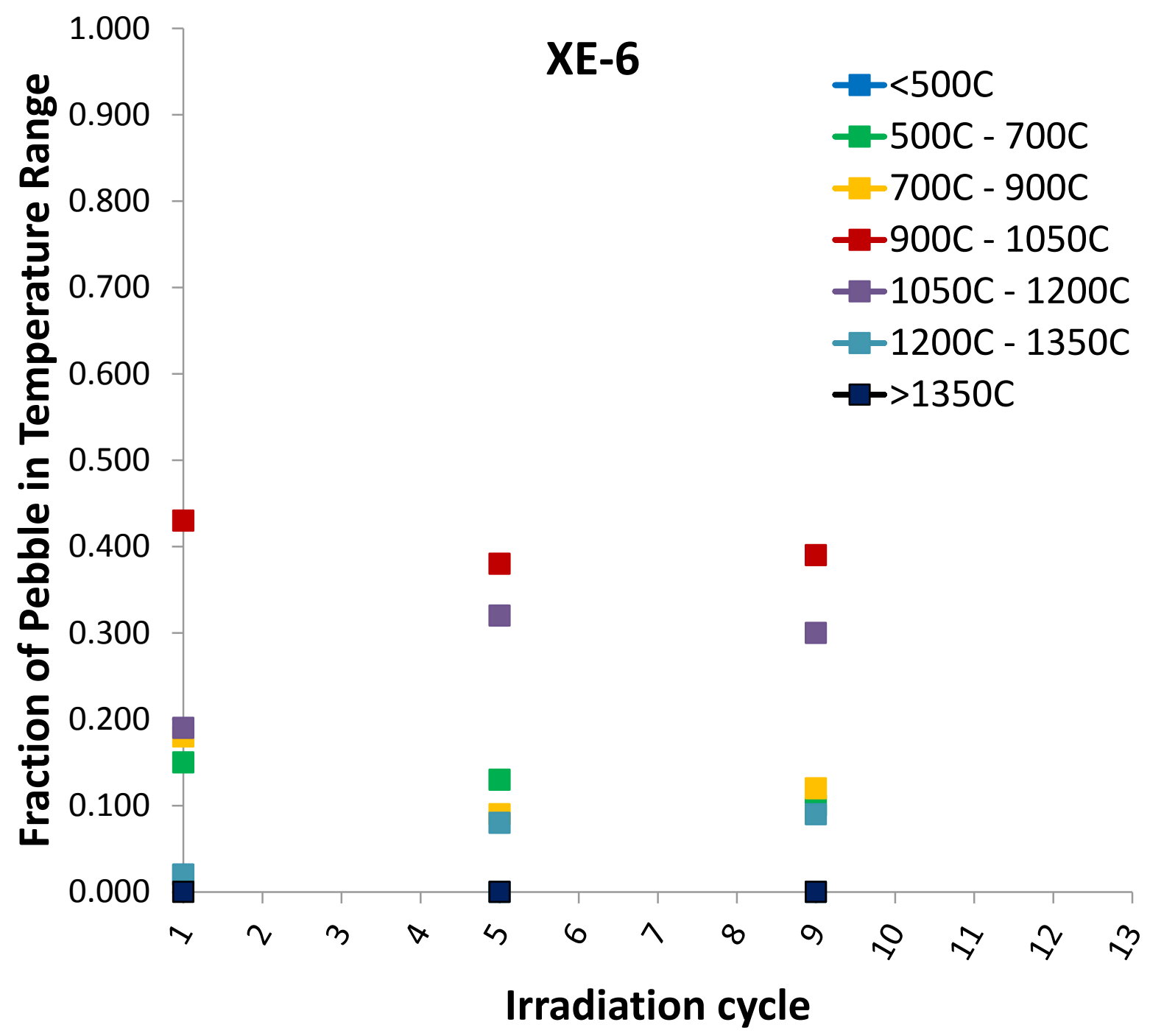

Figure 15. Fraction of fuel particles in each temperature range of XE-6. 


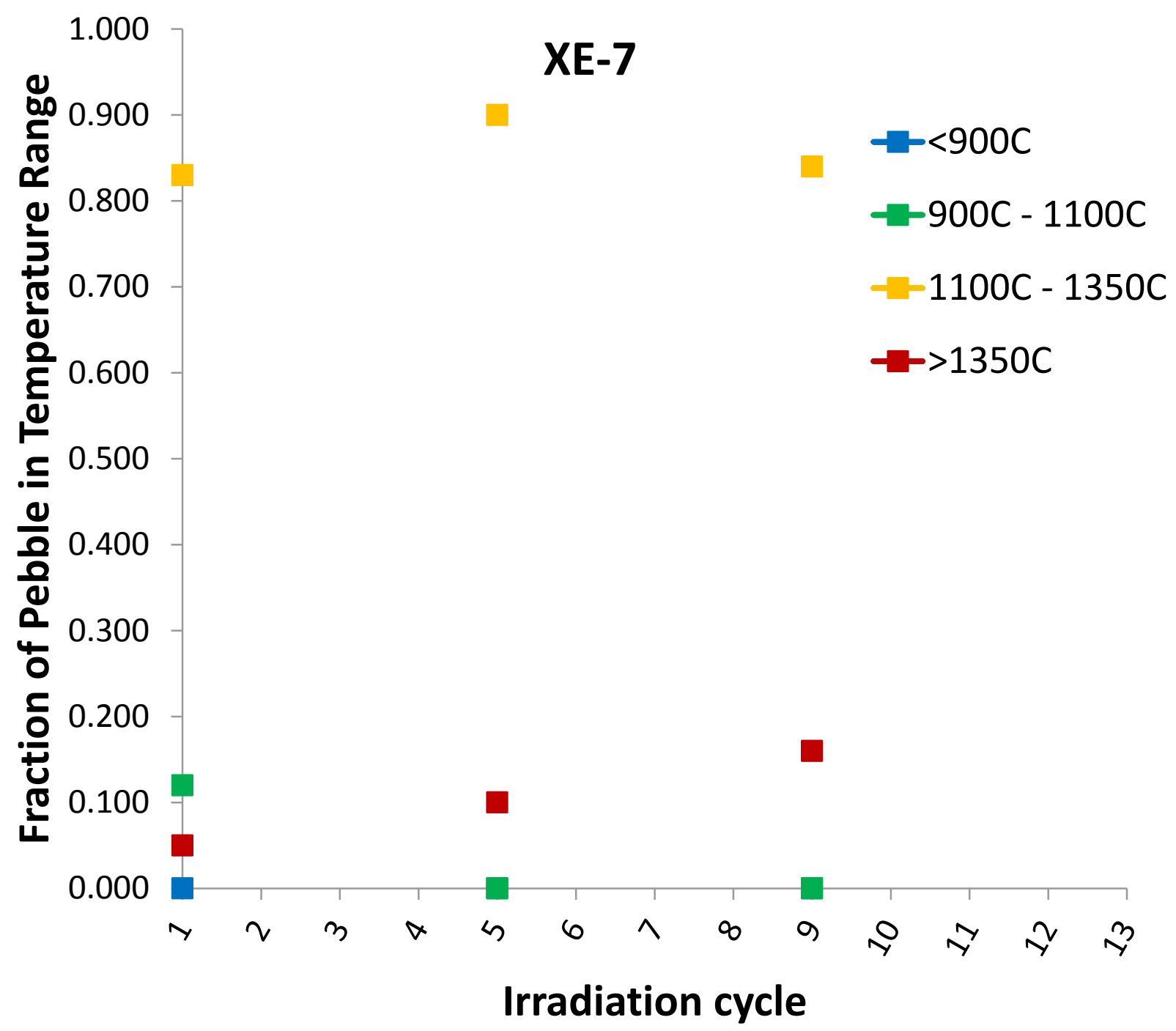

Figure 16. Fraction of fuel particles in each temperature range of XE-7. 


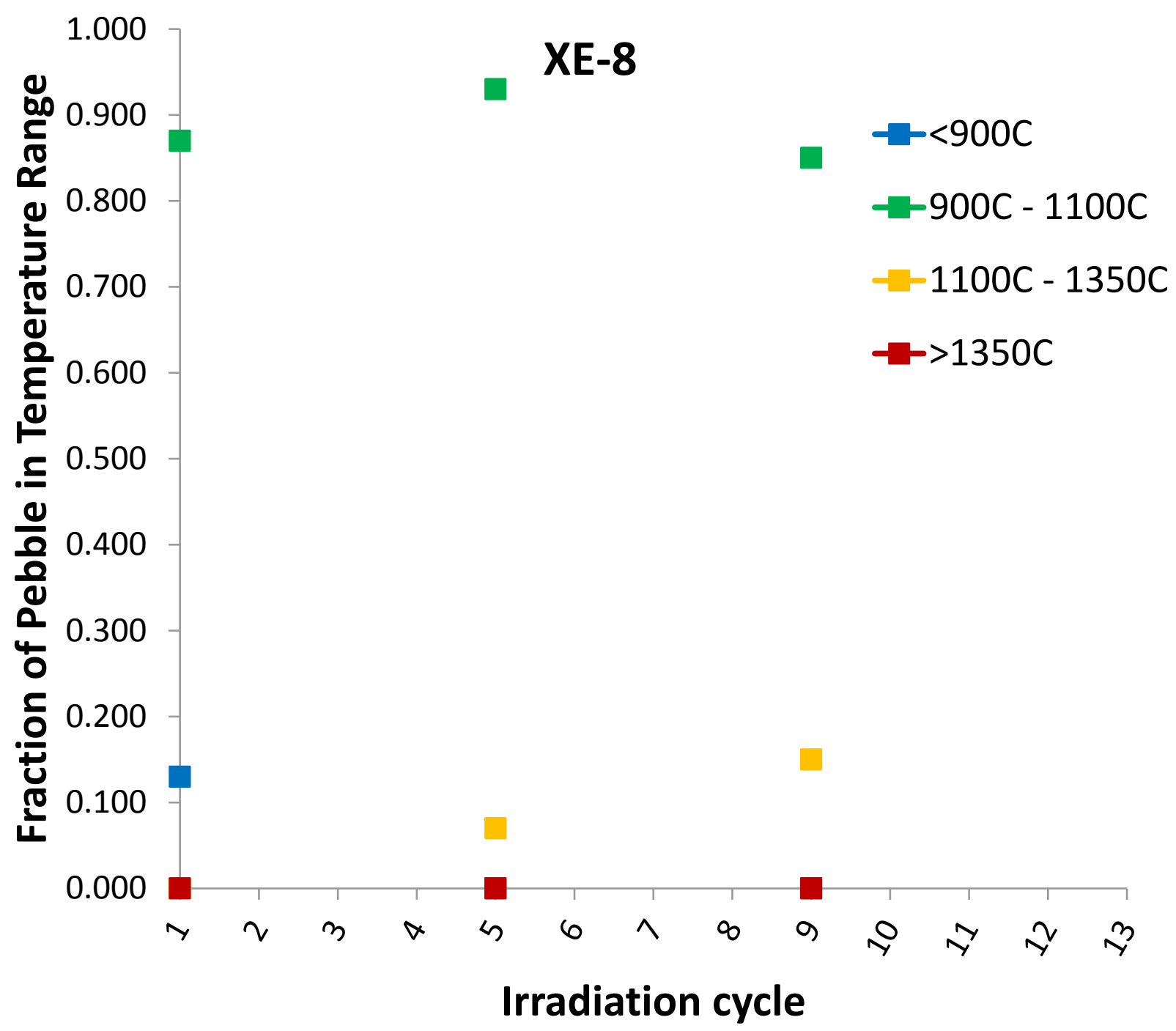

Figure 17. Fraction of fuel particles in each temperature range of XE-8. 


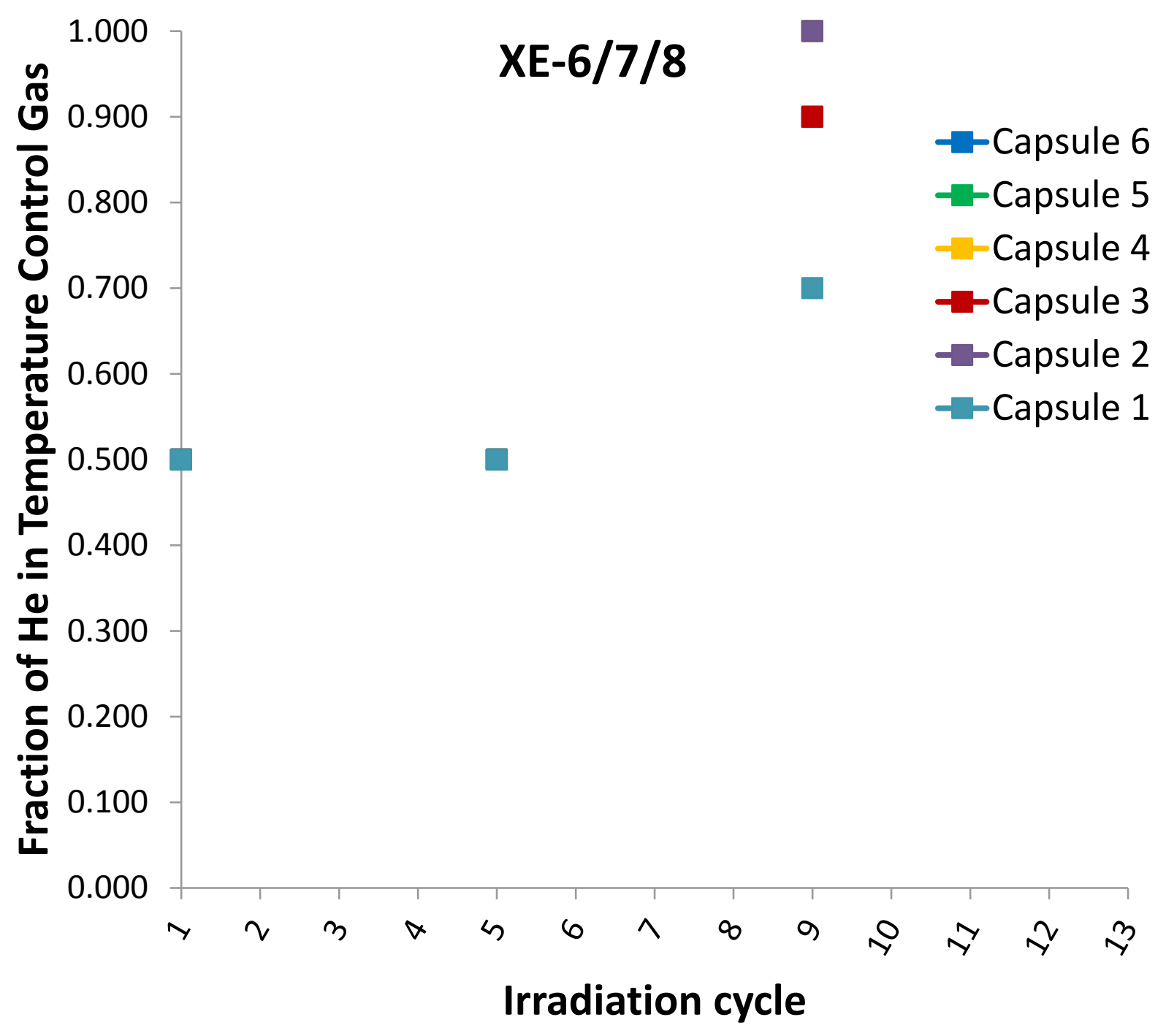

Figure 18. Fraction of helium in temperature control gas in XE-6/7/8.

This analysis shows that the desired temperature distribution can be attained using gas gap temperature control with a separate He-Ne temperature control gas in each capsule. The inside and outside diameter of the graphite holders at room temperature are shown in Table 4 . The holder in capsule 1 consists of an inner ring and an outer ring with a gas gap between them. The diameter of the pebbles is $6.00 \mathrm{~cm}$, while the inside diameter of the capsules is $8.85 \mathrm{~cm}$. The resulting temperature control gas gaps at room temperature varies from 0.025 to $0.075 \mathrm{~cm}$, which is within the desired range previously stated. 
Table 4. Diameter (cm) of Graphite Holders.

\begin{tabular}{|c|c|c|c|}
\hline $\begin{array}{c}\text { Holder } \\
\text { Number }\end{array}$ & Experiment & $\begin{array}{c}\text { Outside Diameter at Room } \\
\text { Temperature }\end{array}$ & $\begin{array}{c}\text { Inside Diameter at Room } \\
\text { Temperature }\end{array}$ \\
\hline 1 (inner layer) & XE-8 & 7.356 & 6.010 \\
\hline 1 (outer layer) & XE-8 & 8.725 & 7.417 \\
\hline 2 & XE-6 & 8.725 & 6.010 \\
\hline 3 & XE-7 & 8.700 & 6.010 \\
\hline 4 & XE-6 & 8.750 & 6.010 \\
\hline 5 & XE-6 & 8.760 & 6.010 \\
\hline 6 & XE-6 & 8.801 & 6.010 \\
\hline
\end{tabular}

\subsection{Instrumentation}

The design illustrated in Section 2.3 (see also Figure 14) relies on the concept of "thru-tubes," which are metallic conduits passing through the bodies of the capsules to provide a means of routing the thermocouples from lower capsules up through the bodies of upper capsules. The thru-tubes are used to separate the gas in the capsules from the gas in the thru-tubes and the gas plenums between the capsules. This arrangement allows for each capsule to have an isolated gas environment. The number and size of the thermocouples are limited by the number and diameter of the thru-tubes. This layout assumed four thru-tubes with outer and inner diameters of $8.3 \mathrm{~mm}$ and $7.7 \mathrm{~mm}$, respectively. With this design, there is sufficient room for seven or eight 1.5-mm-diameter thermocouples and two 1.5-mm gas lines in each capsule. Figure 5 shows typical locations of thermocouples and gas lines.

In Figure 6, the thermocouples are shown terminating in the both the graphite holders a few millimeters from the pebbles themselves, and in the unfueled rind material of the pebbles. Placing a few thermocouples in the rinds of some of the pebbles will be advantageous from the standpoint of reducing the uncertainty in the pebble fuel temperature. However, this would complicate assembly and perhaps post irradiation examination (PIE) as well.

In either location, depending on the thermocouple sheath material, it may be necessary to place a protective sleeve between the thermocouple sheath and the graphite holder (or pebble rind). Experience with AGR-2 indicates that TRISO particle SiC failure can be induced by nickel attack. The source of the nickel was apparently from thermocouples placed within 2 or $3 \mathrm{~mm}$ of the fuel compacts. Because nearly all thermocouple sheaths incorporate large amounts of nickel (or other first-row transition elements), the AGR series of experiments took the precaution of sleeving all standard thermocouples with refractory metal tubes.

Figure 5 shows neutron fluence wires within tubes welded at four locations around the filter housing. An advantage of placing the fluence wires external to the experiment is that they can be read after each reactor cycle and compared with the as-run physics analyses. This arrangement was adopted for the AGR-3/4 and AGR-5/6/7 experiments.

Including fluence wires within the capsules themselves is also an option. Having fluence wires closer to the fuel is definitely and advantage, however they cannot be read until the test is entirely completed. Retrieval and reading and reading of the wires would add to the PIE cost. 


\subsection{Experiment Sizing and Shipping}

It is assumed that the XE-6/7/8 experiment will be shipped to the Materials and Fuels Complex on the INL Site for PIE. The AGR-3/4 test was shipped using the GE-2000 cask with an INL cask liner. AGR-5/6/7 is planned to be shipped using an INL site-only cask called the Dry Transfer Cubicle Cask Insert (DTCCI) with overpack, which is likely to be the shipping method that will work best for XE-6/7/8. Due to the length of the GE-2000 cask, the maximum test length that could be shipped for AGR-3/4 was about $109 \mathrm{~cm}$. AGR-3/4 was longer than this and required two shipments because it had to be cut into two pieces. Plans are to also cut AGR-5/6/7 into two pieces and ship them separately. In the current layout, XE-6/7/8 is about $15 \mathrm{~cm}$ shorter than the two AGR tests. As such, it may be possible to ship the entire core section in one shipment.

\section{SUMMARY AND RECOMMENDATIONS}

1. The in-core design consists of six capsules with four capsules housing a single pebble and two with double pebbles for a total of eight pebbles in the test train. The test train diameter is $9.55 \mathrm{~cm}$, and the overall in-core length is about $109 \mathrm{~cm}$.

2. The above-core portion of the test would be very similar to AGR-5/6/7, with some components being identical to the AGR-5/6/7 experiment.

3. Instrumentation for the XE-6/7/8 test would be similar to the AGR-5/6/7 test, consisting of approximately seven $1.5-\mathrm{mm}$ thermocouples per capsule and four fluence wires external to the capsule.

4. The scoping physics and thermal analyses performed for this study indicate that the experiment goals likely can be met in about 450 days of irradiation. Depending on the final design configuration, refinements to the neutron filter schedule, and the ATR NE lobe powers, it may be possible to shorten the irradiation period by one ATR cycle.

5. INL recommends that the XE- 8 capsule be placed at the bottom of the test train because this position does not require thru-tubes and would allow for a spherical graphite shell to be placed around the pebble to capture the fission products.

6. Two changes to the basic capsule design were identified as a part of the thermal analysis: (1) the XE-7 graphite fuel holder will need to be separated into two pieces to produce a temperature reduction in the region of the holder where the thru-tubes pass; and (2) the capsule heads must be modified to reduce the centerline temperature; one method identified to do this is by welding in a tapered nickel insert.

\section{REFERENCES}

1. FOR-368, "Functional and Operational Requirements for the XE-6/7/8 Irradiation Experiment," Rev. 0, June 2018. 


\section{Appendix A - \\ XE-6/7/8 Conceptual Design Drawings}




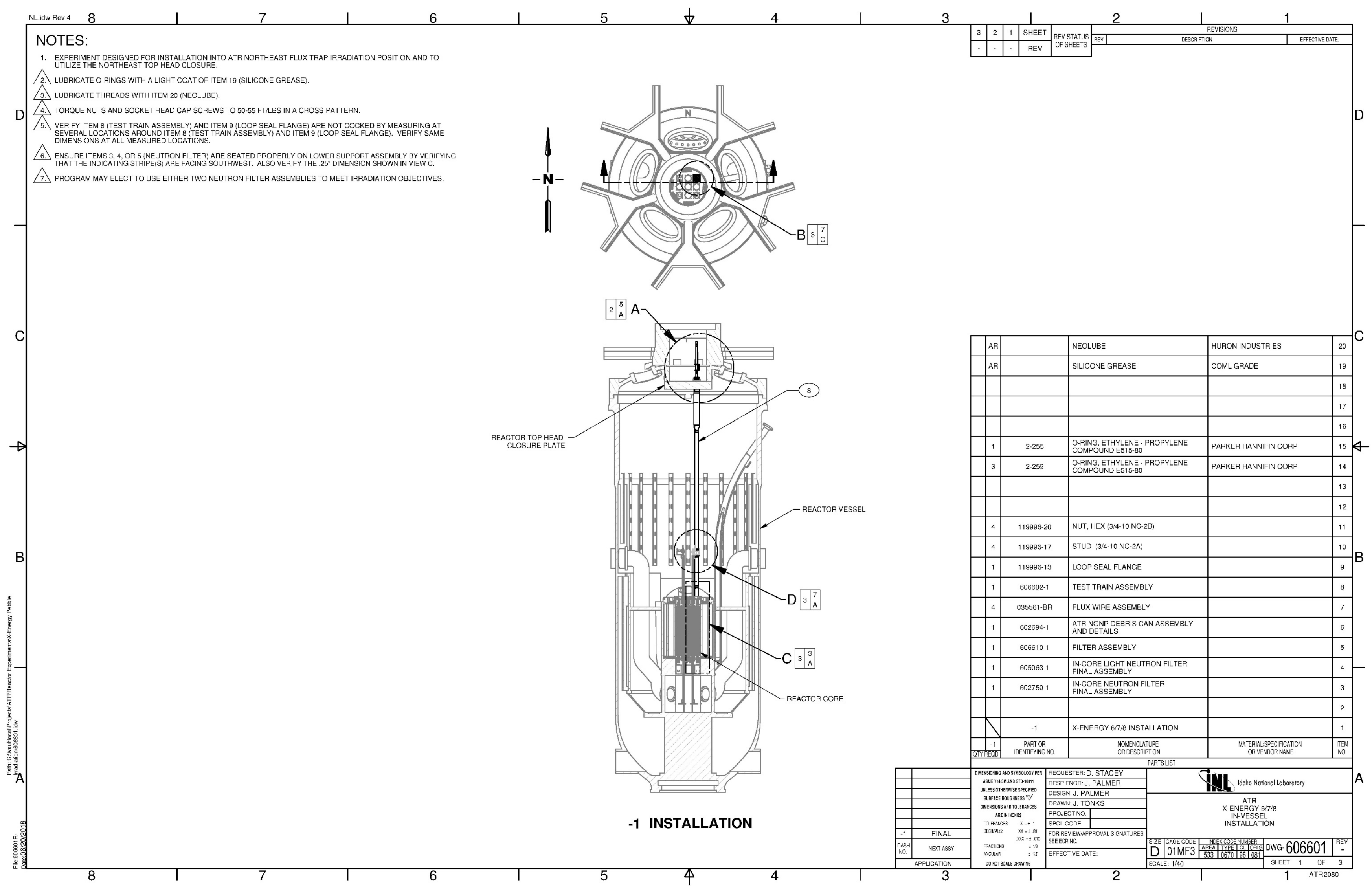




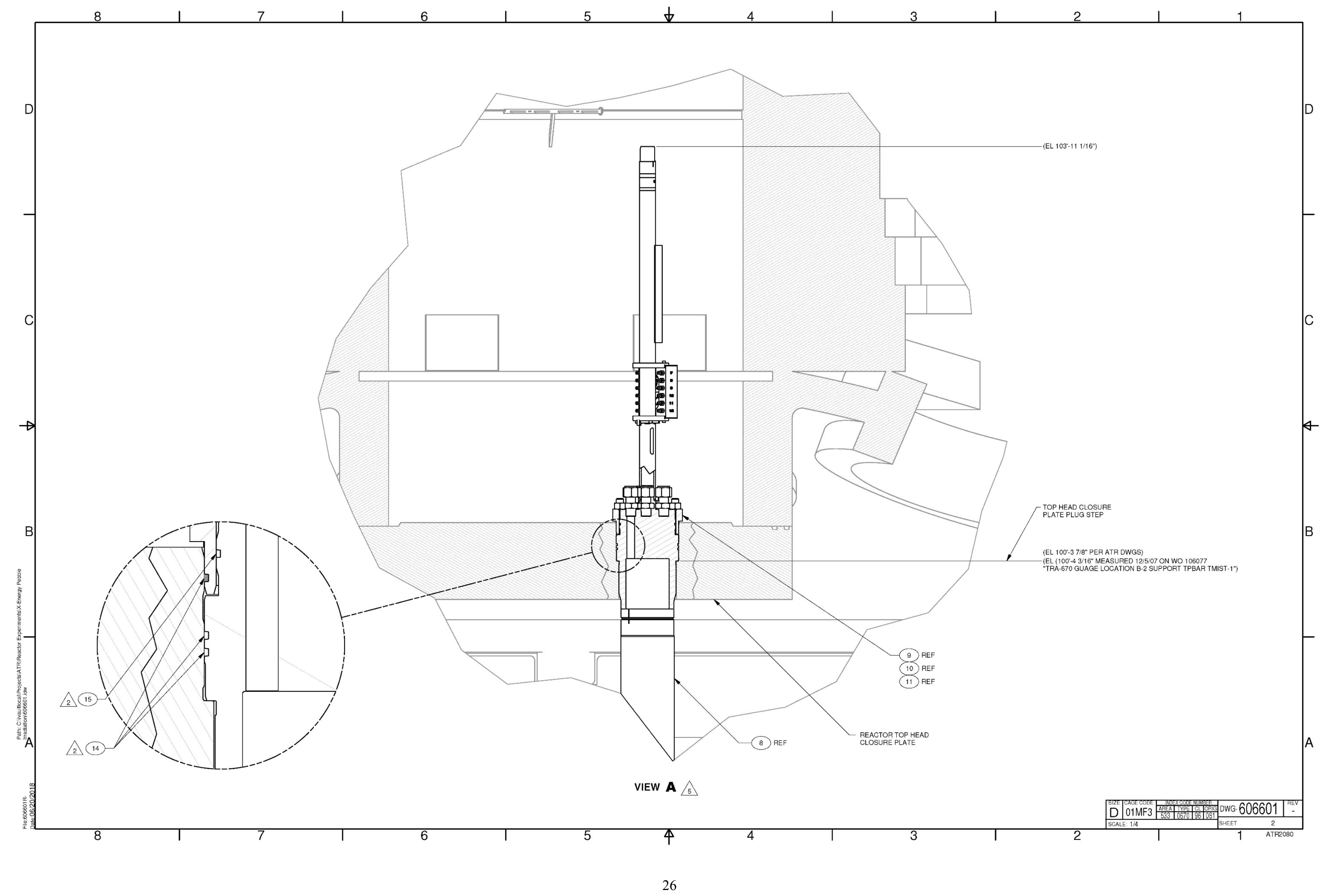




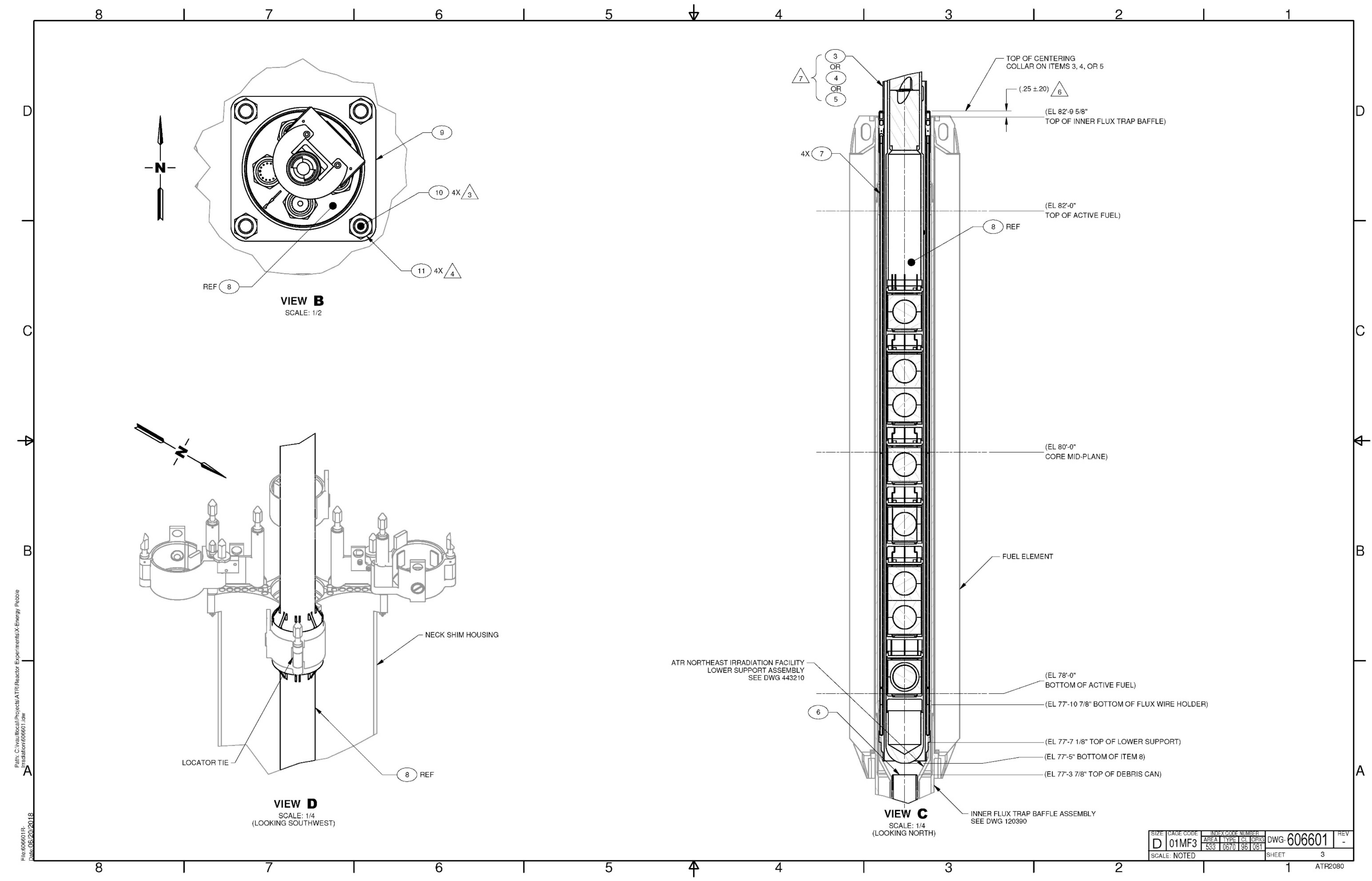




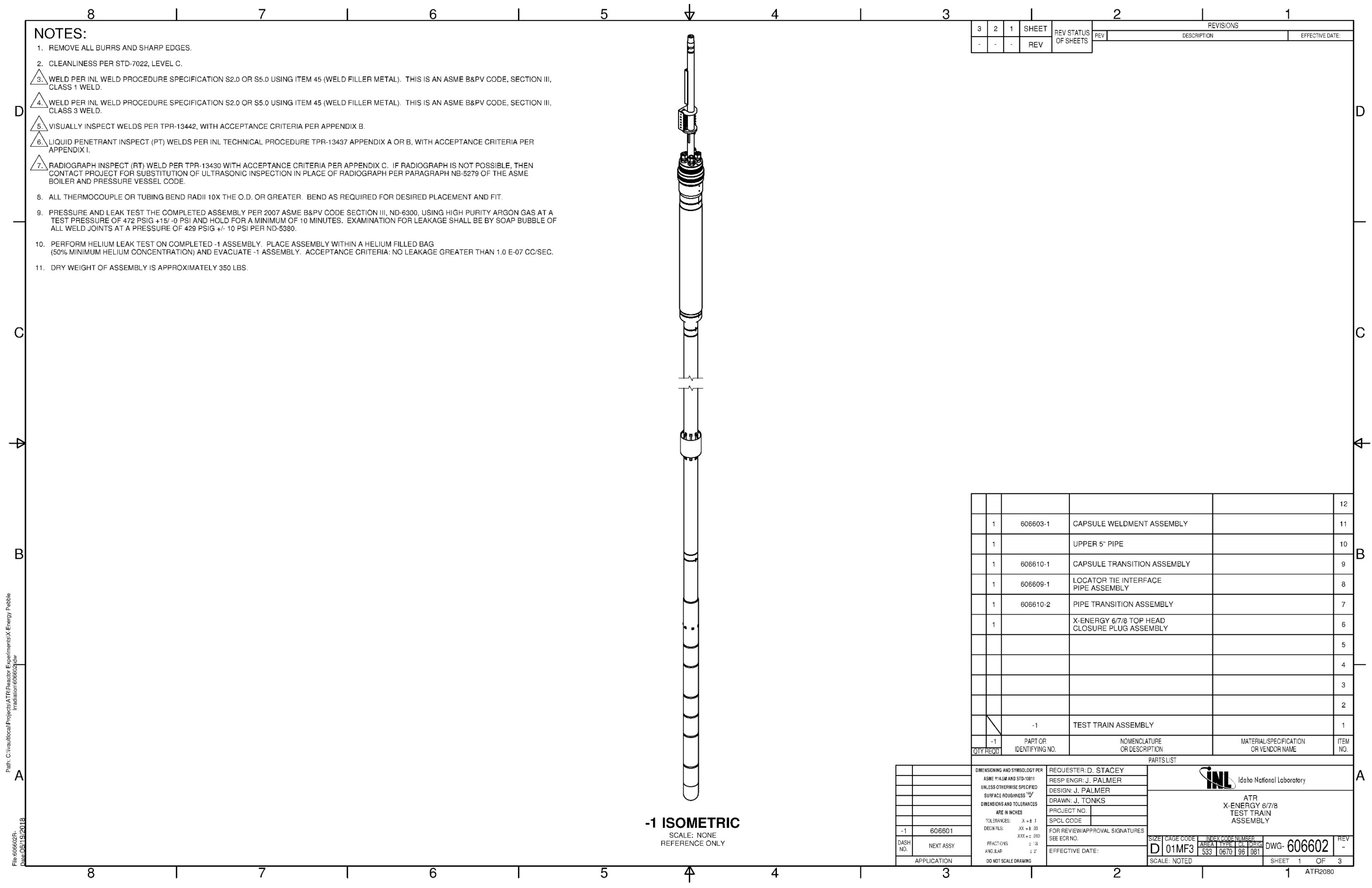




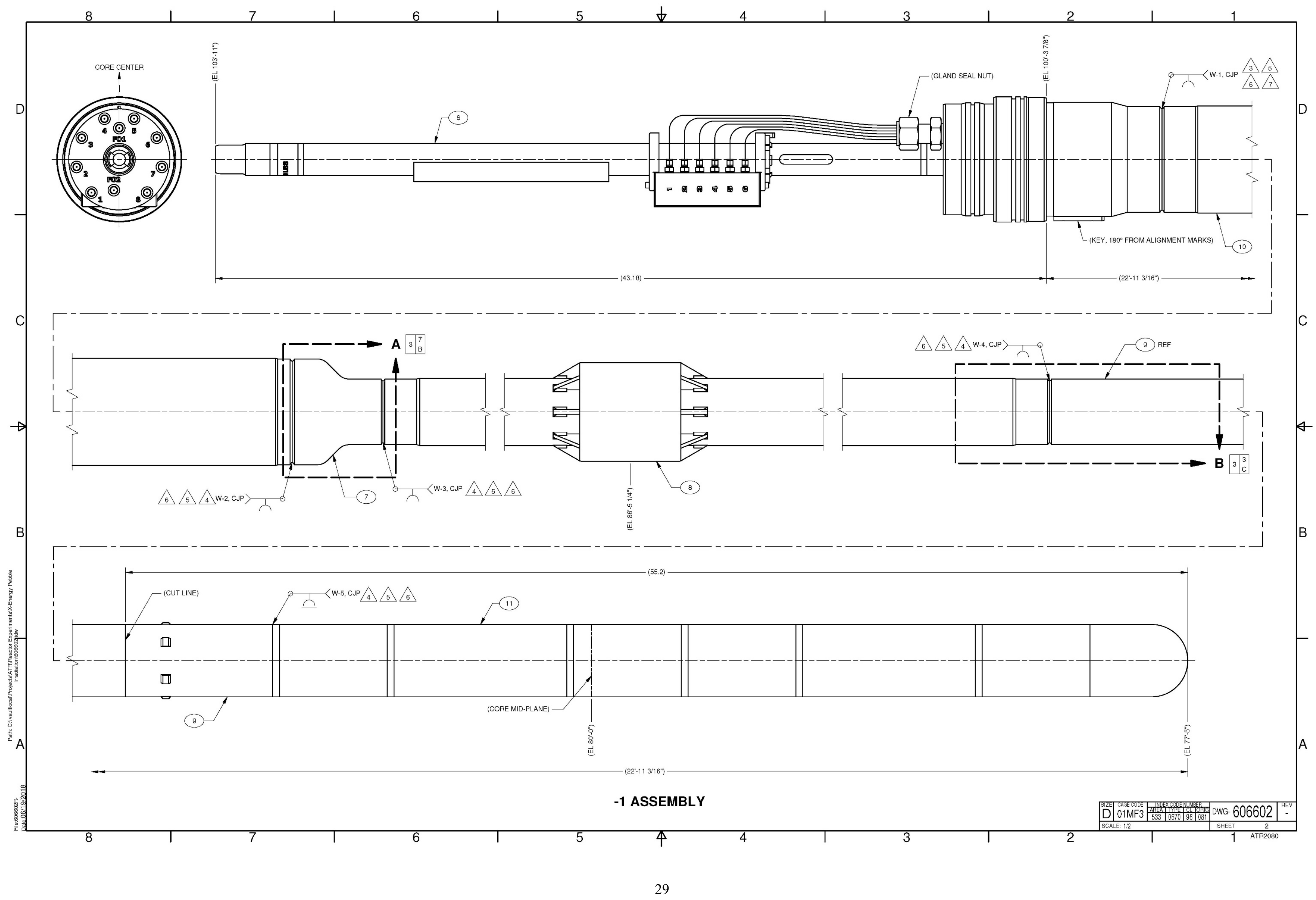




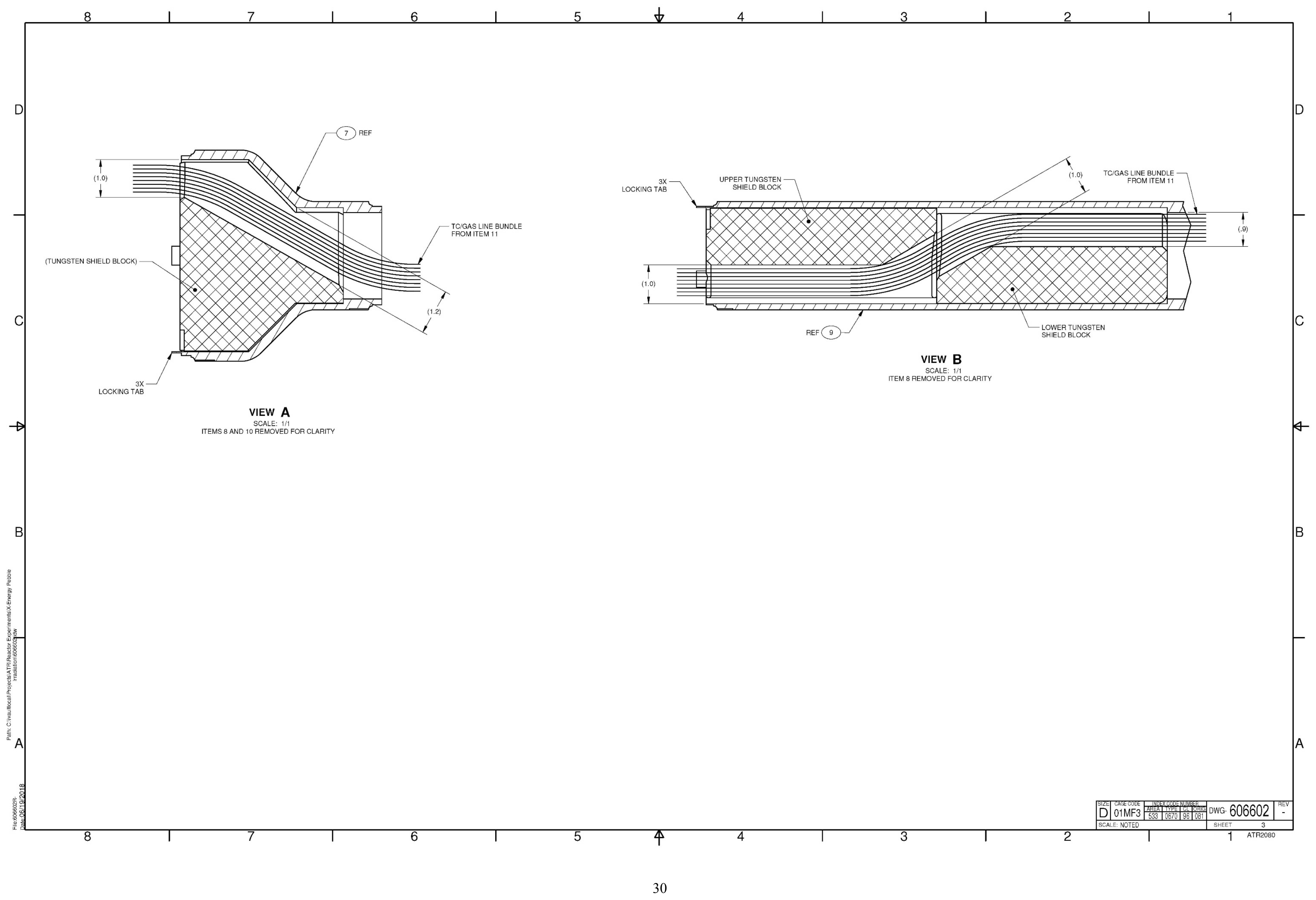




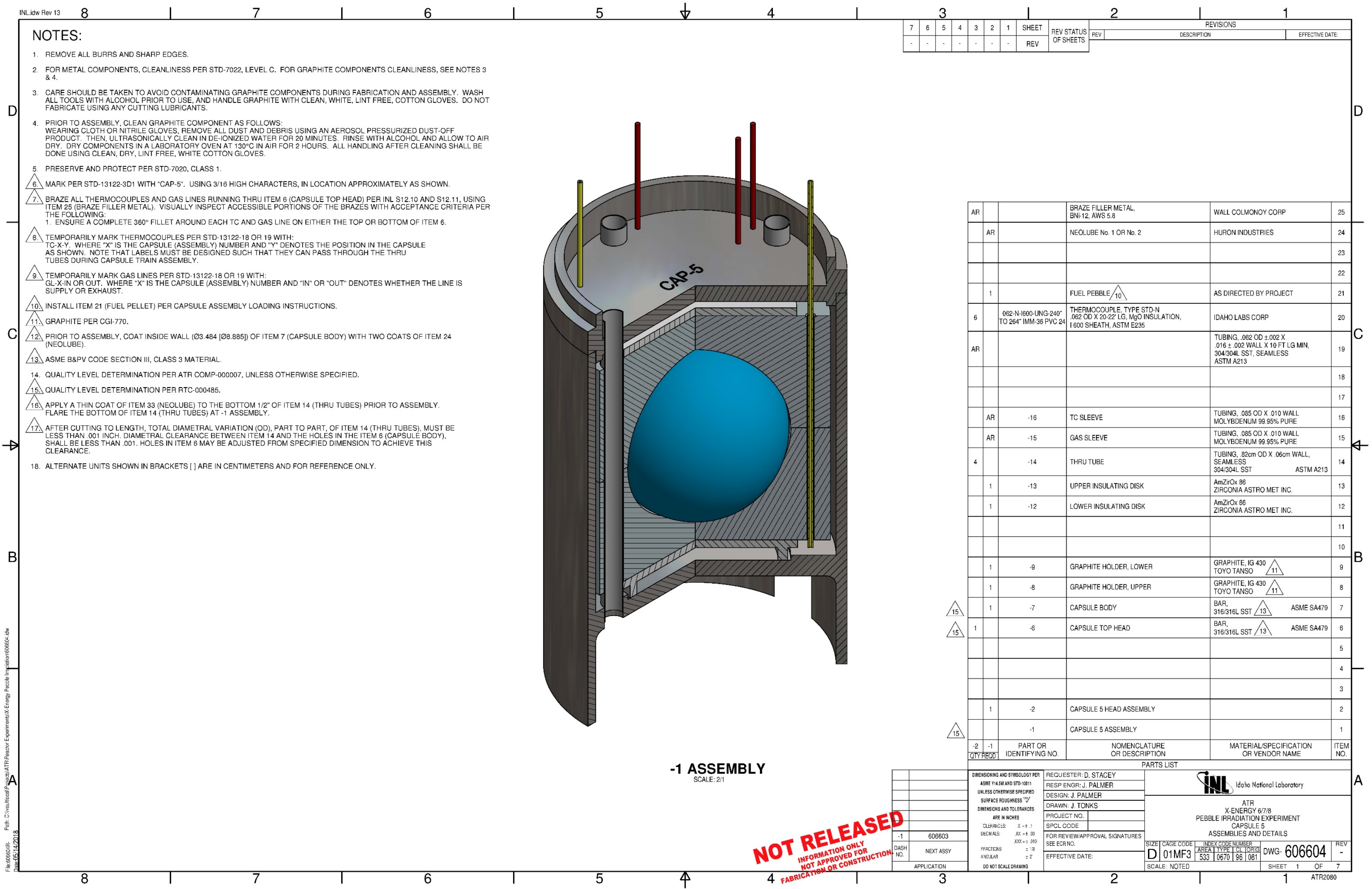




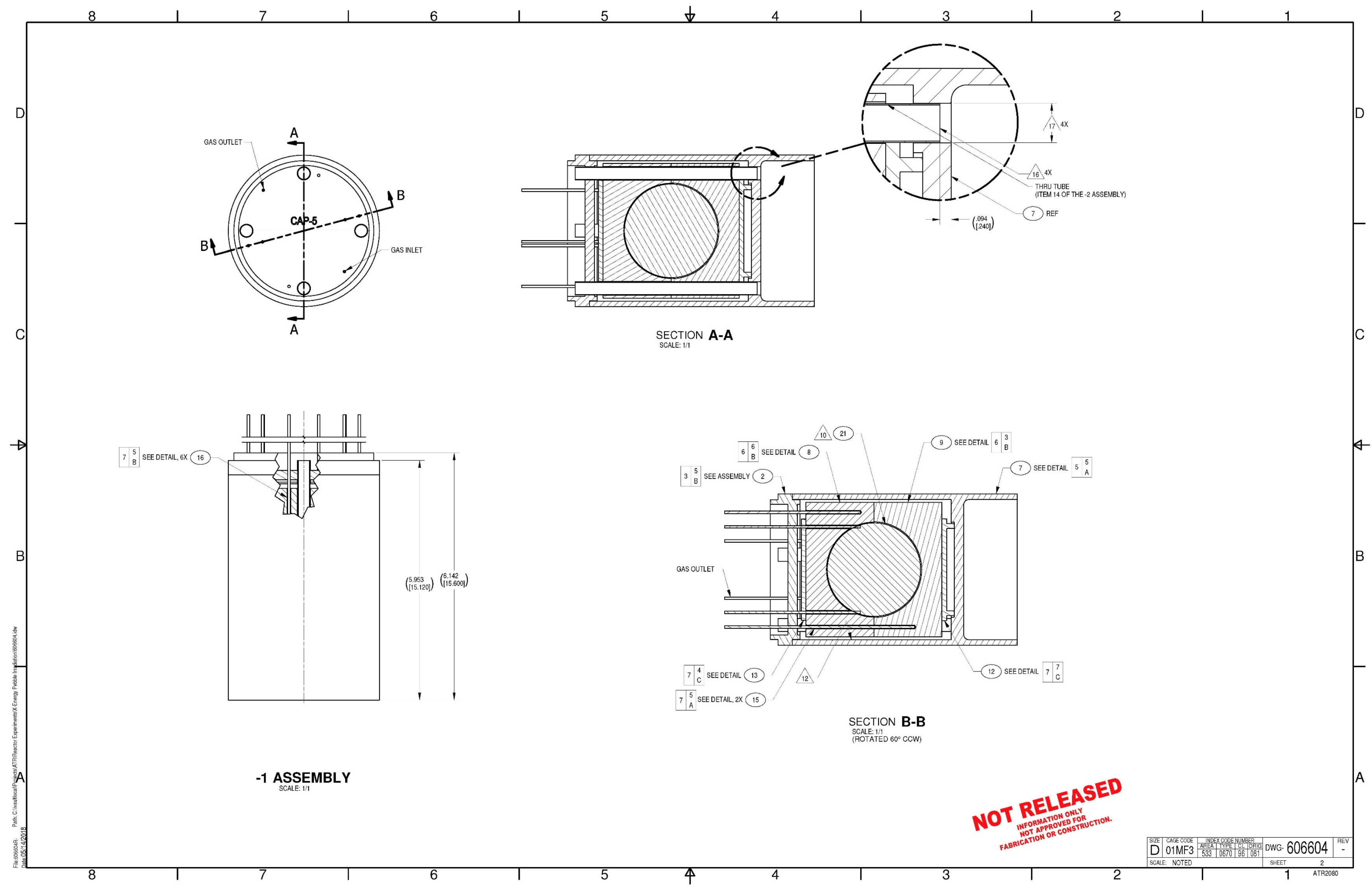




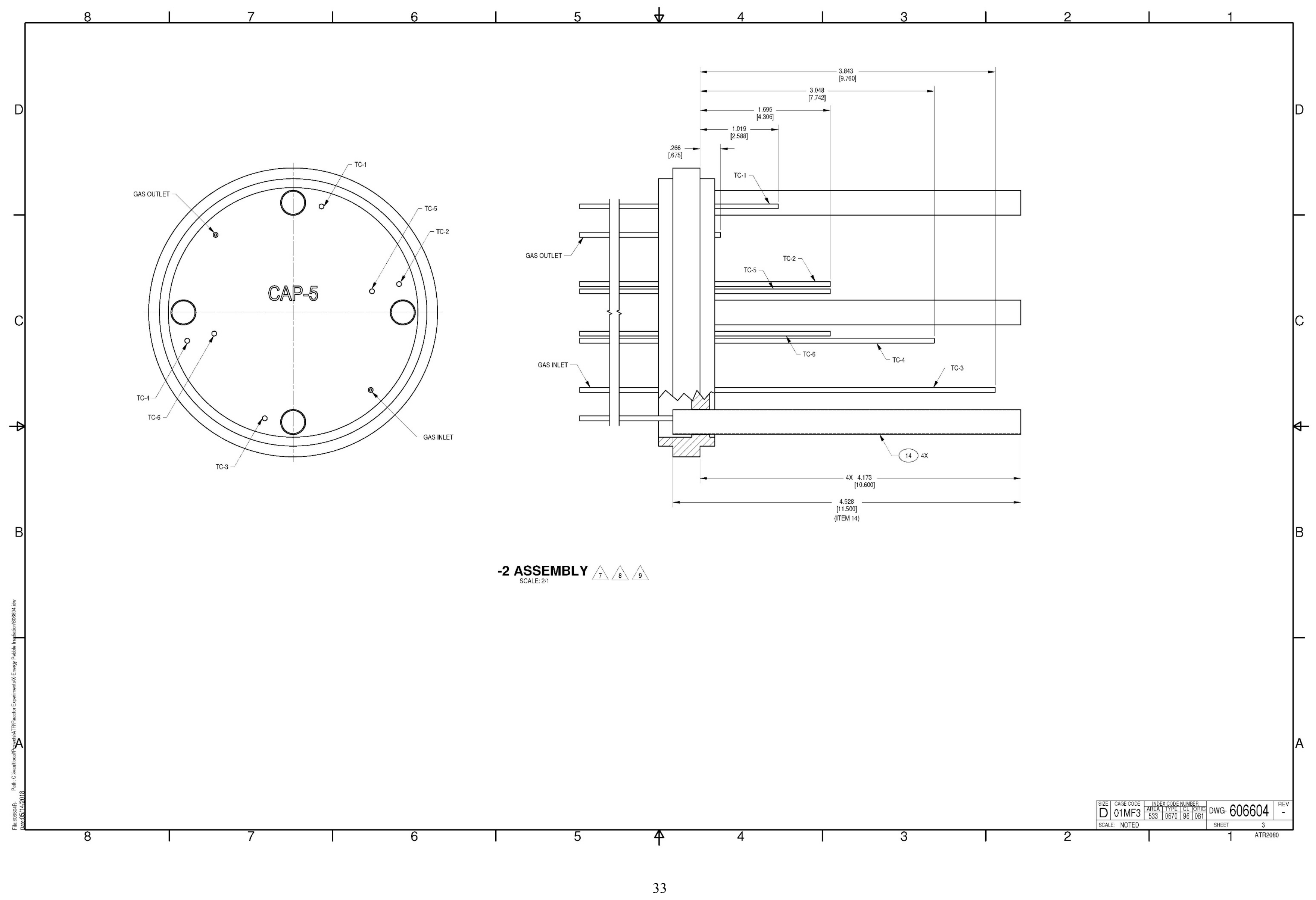




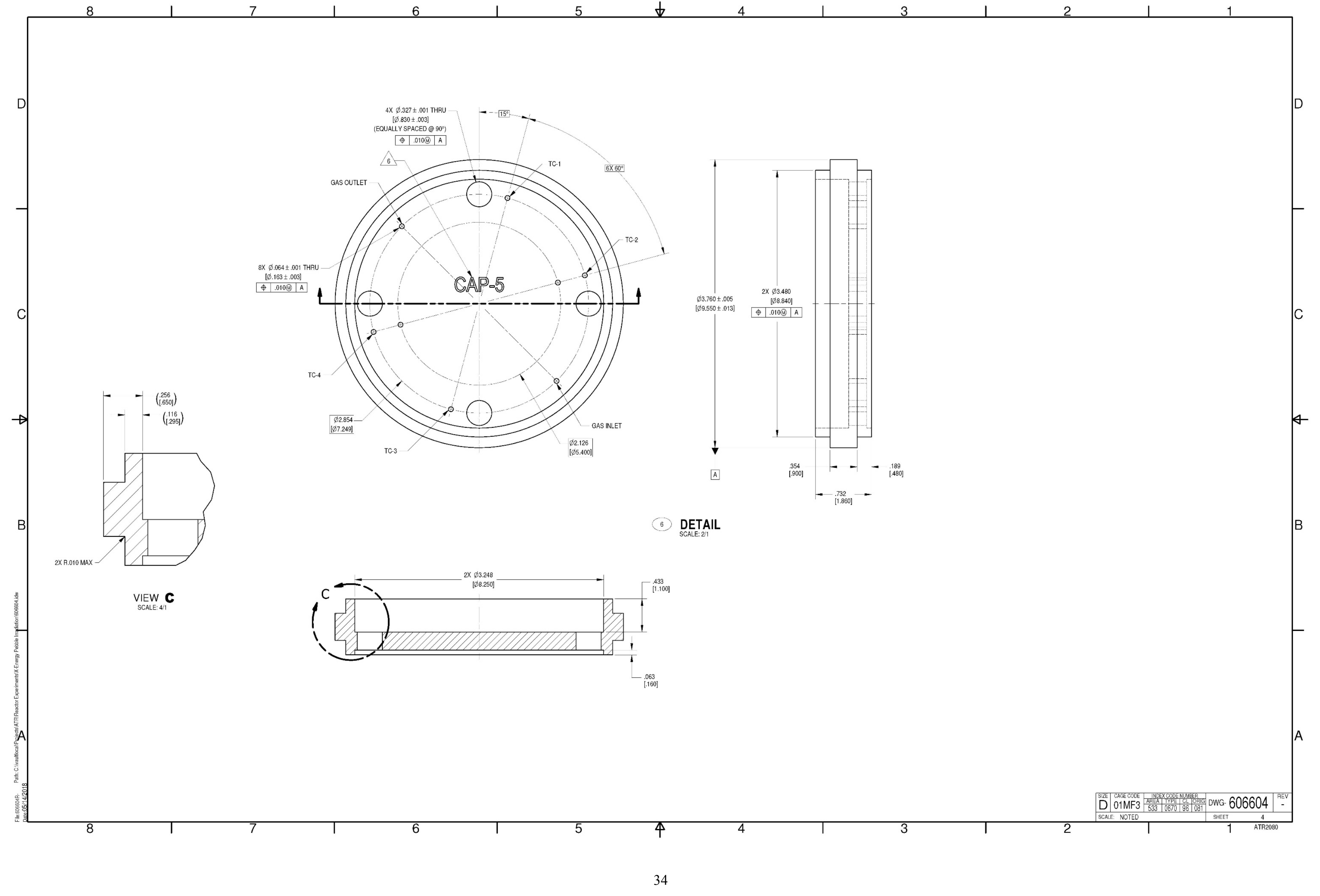




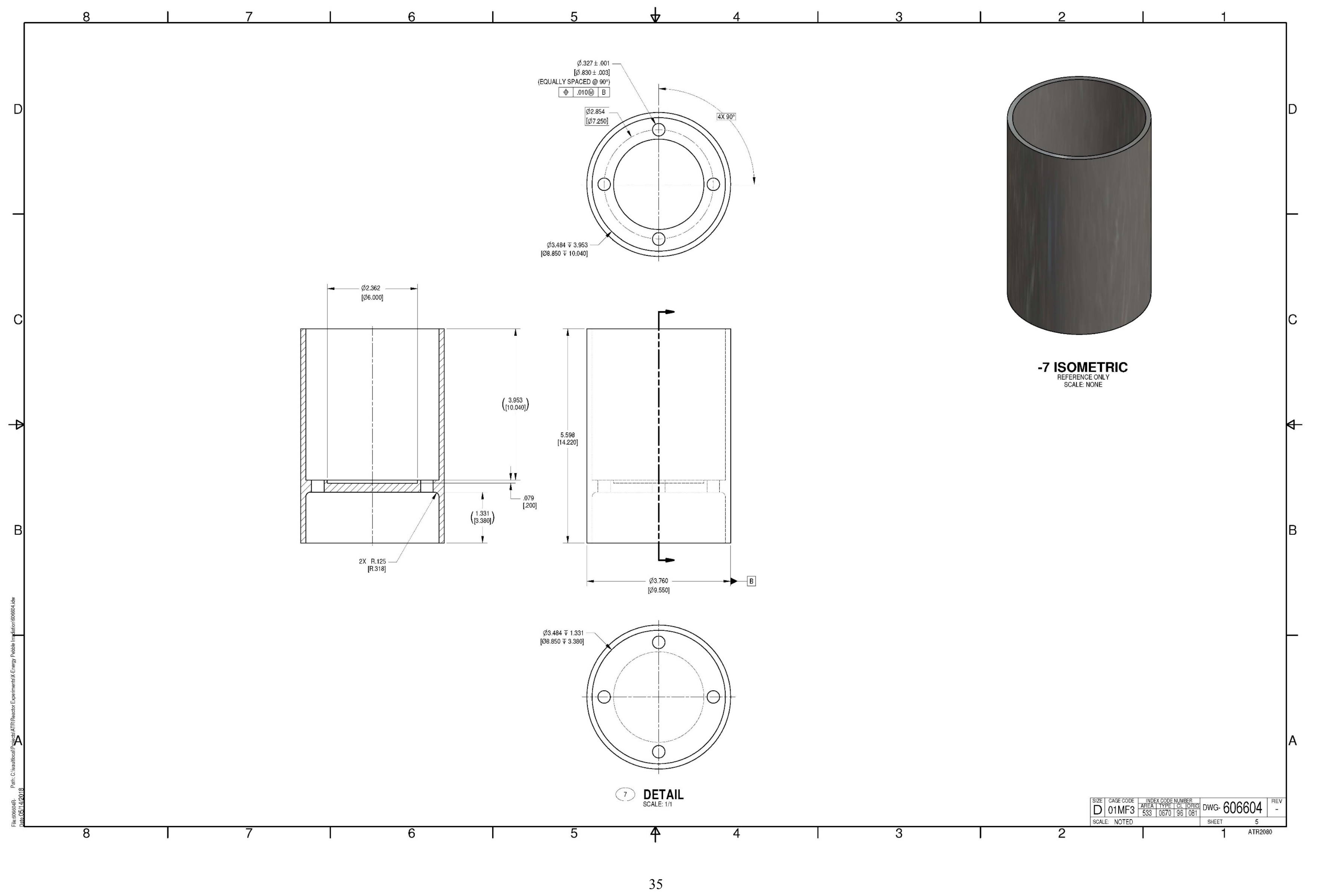




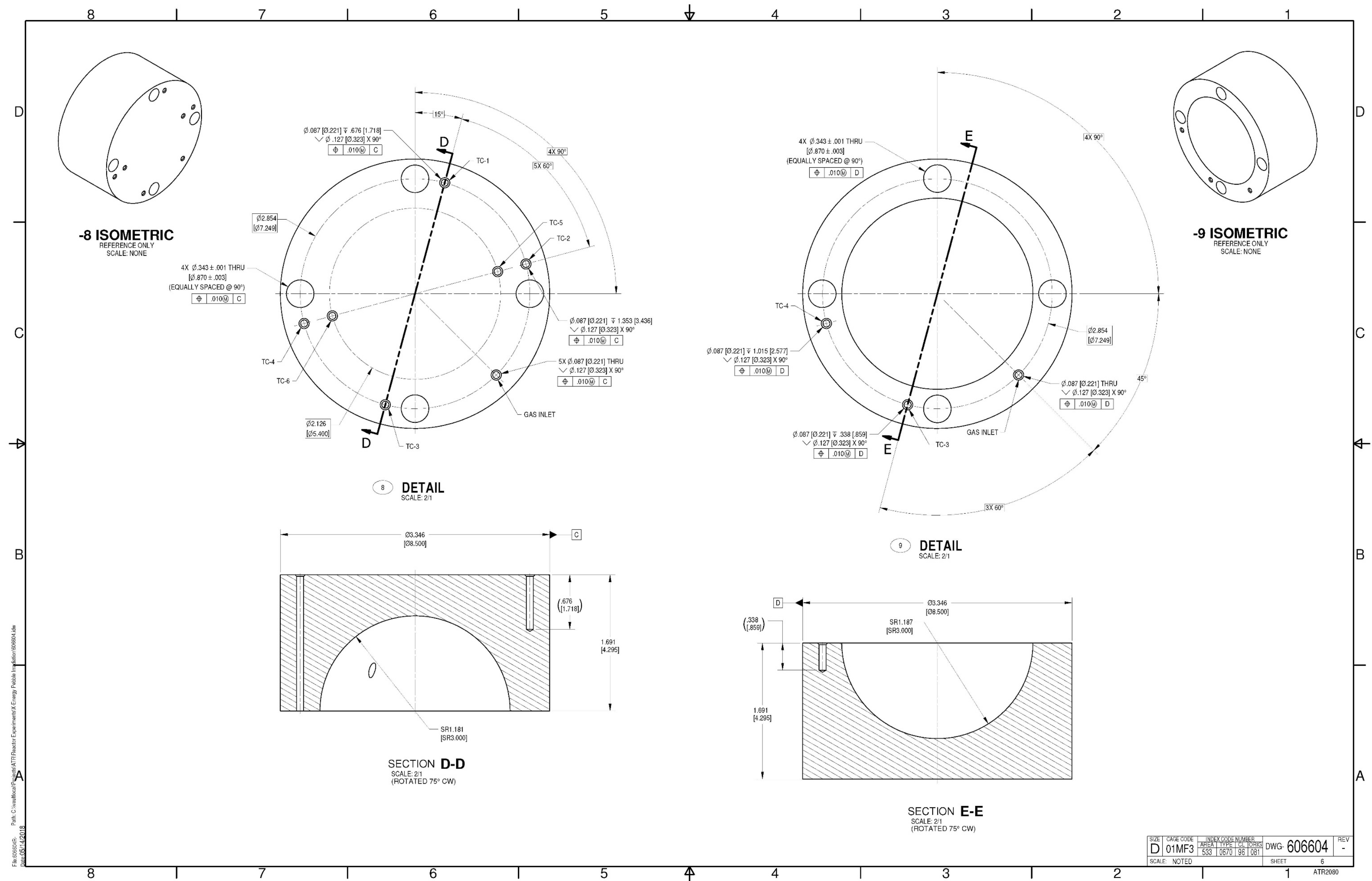




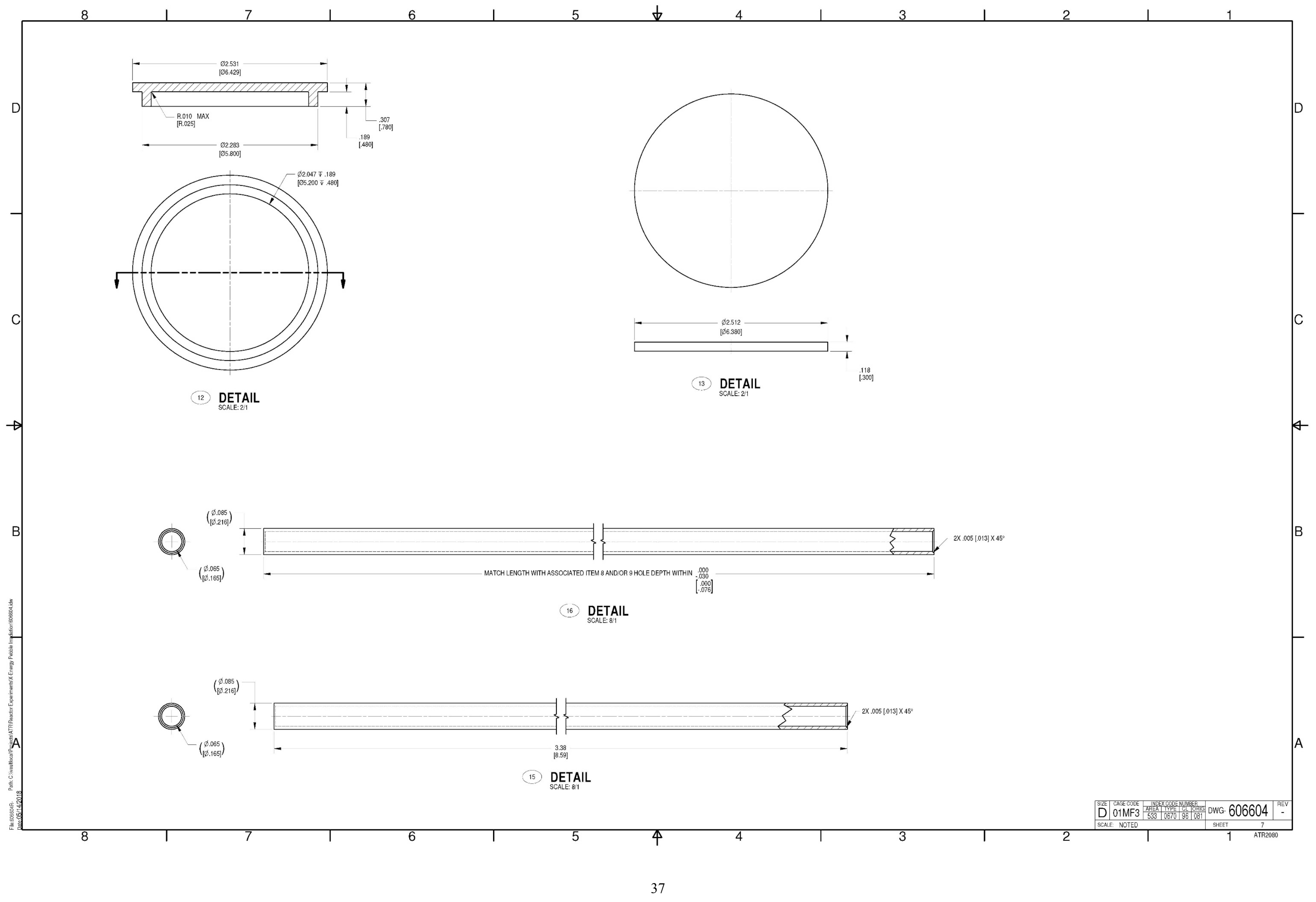




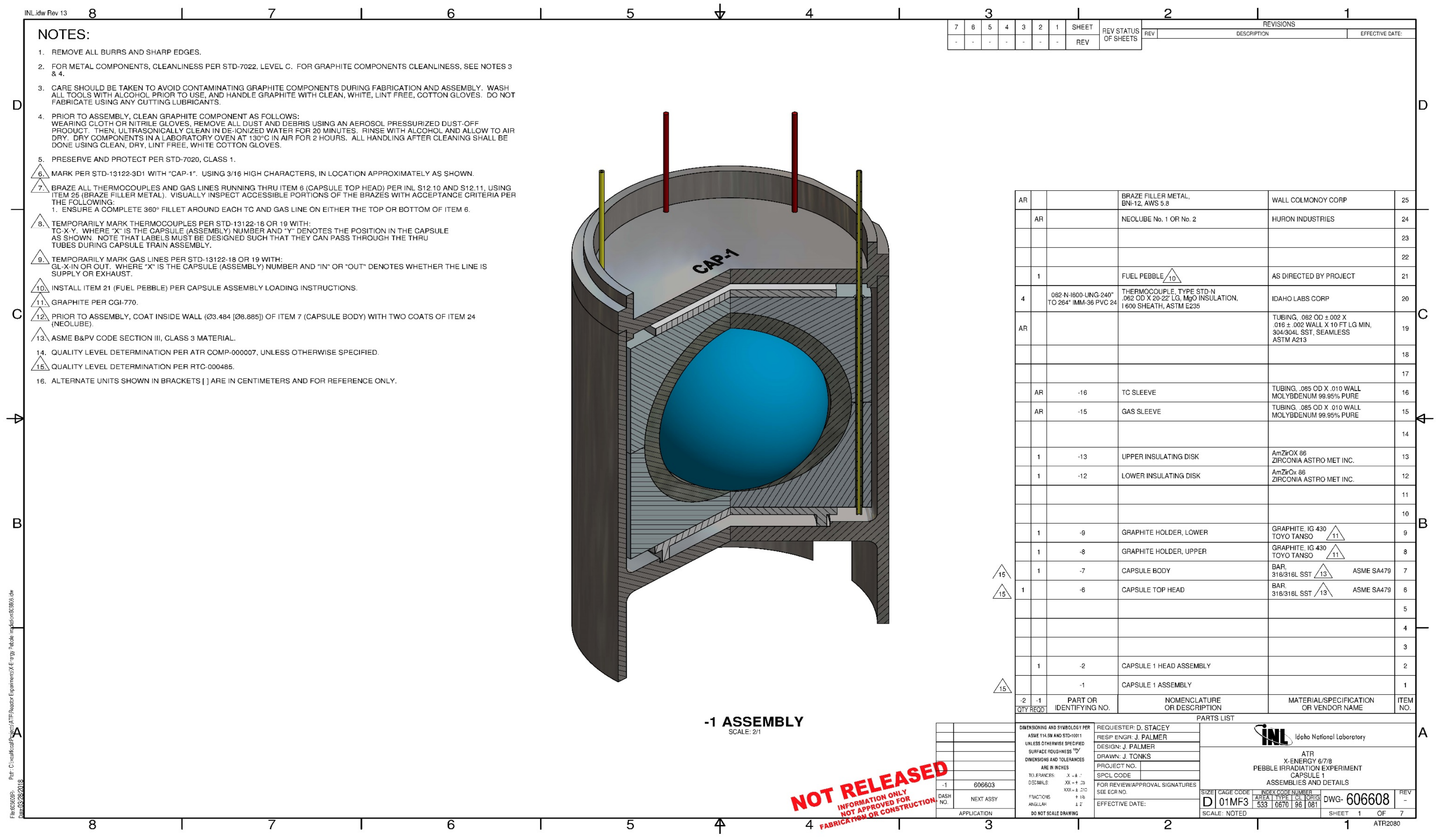




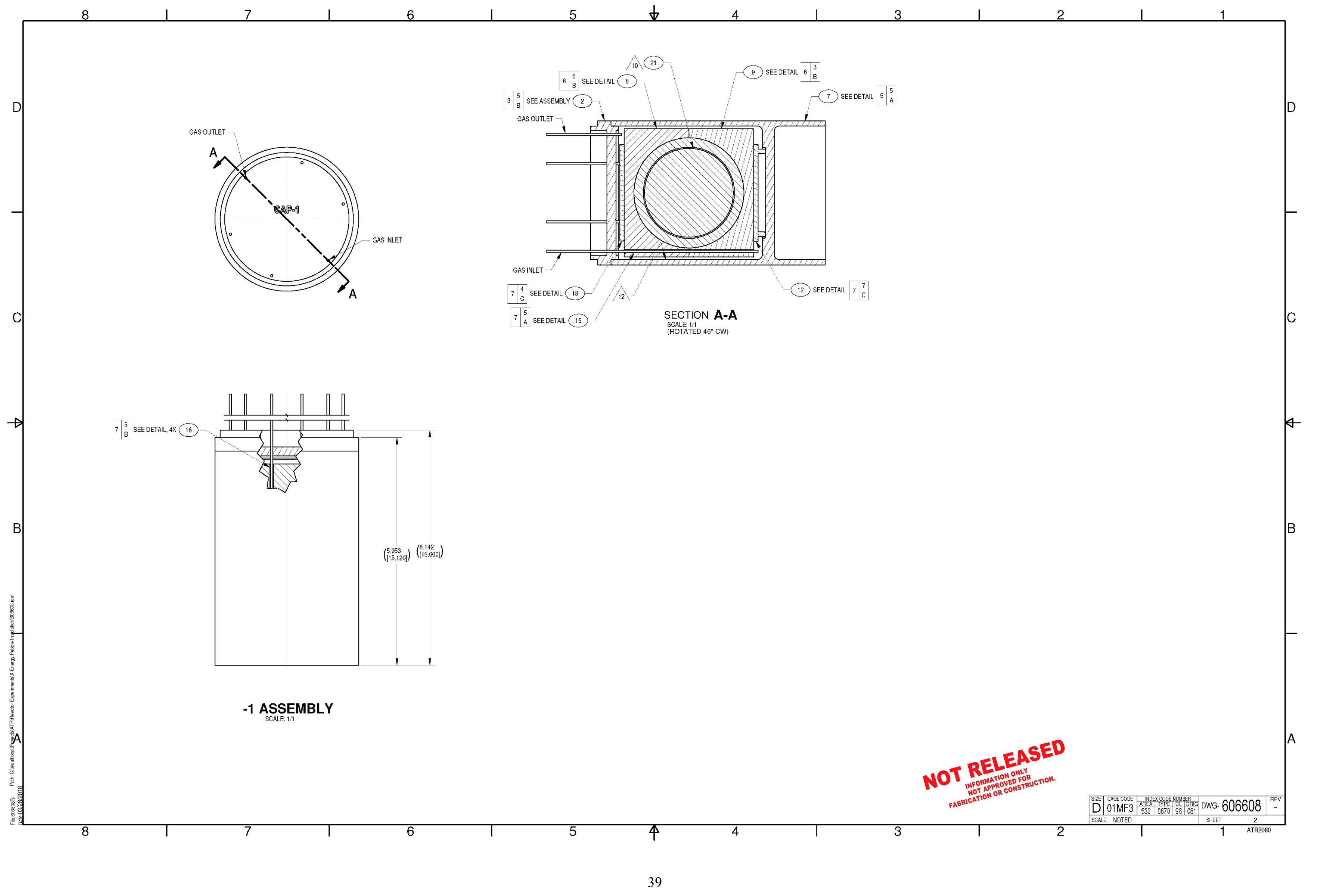




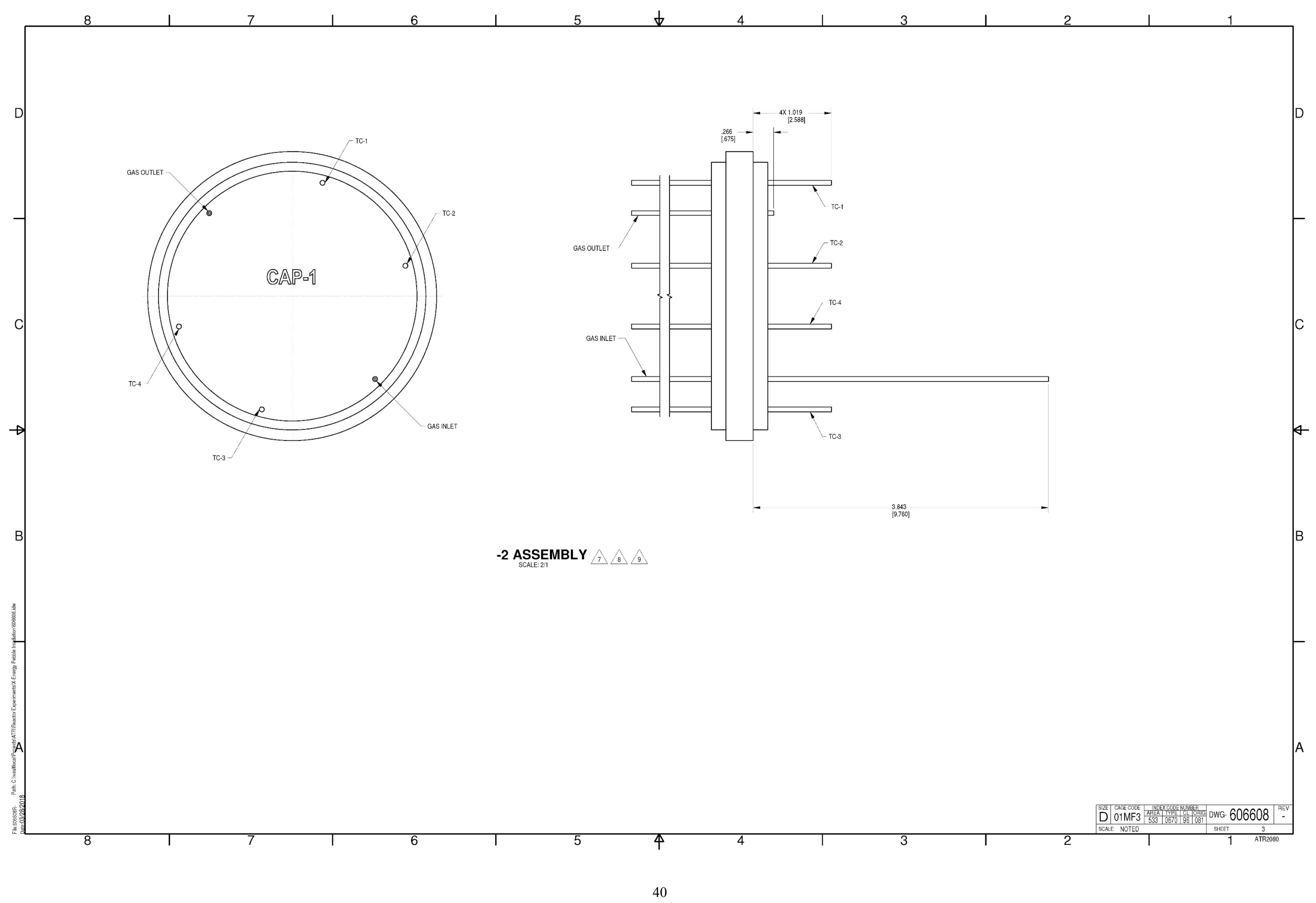




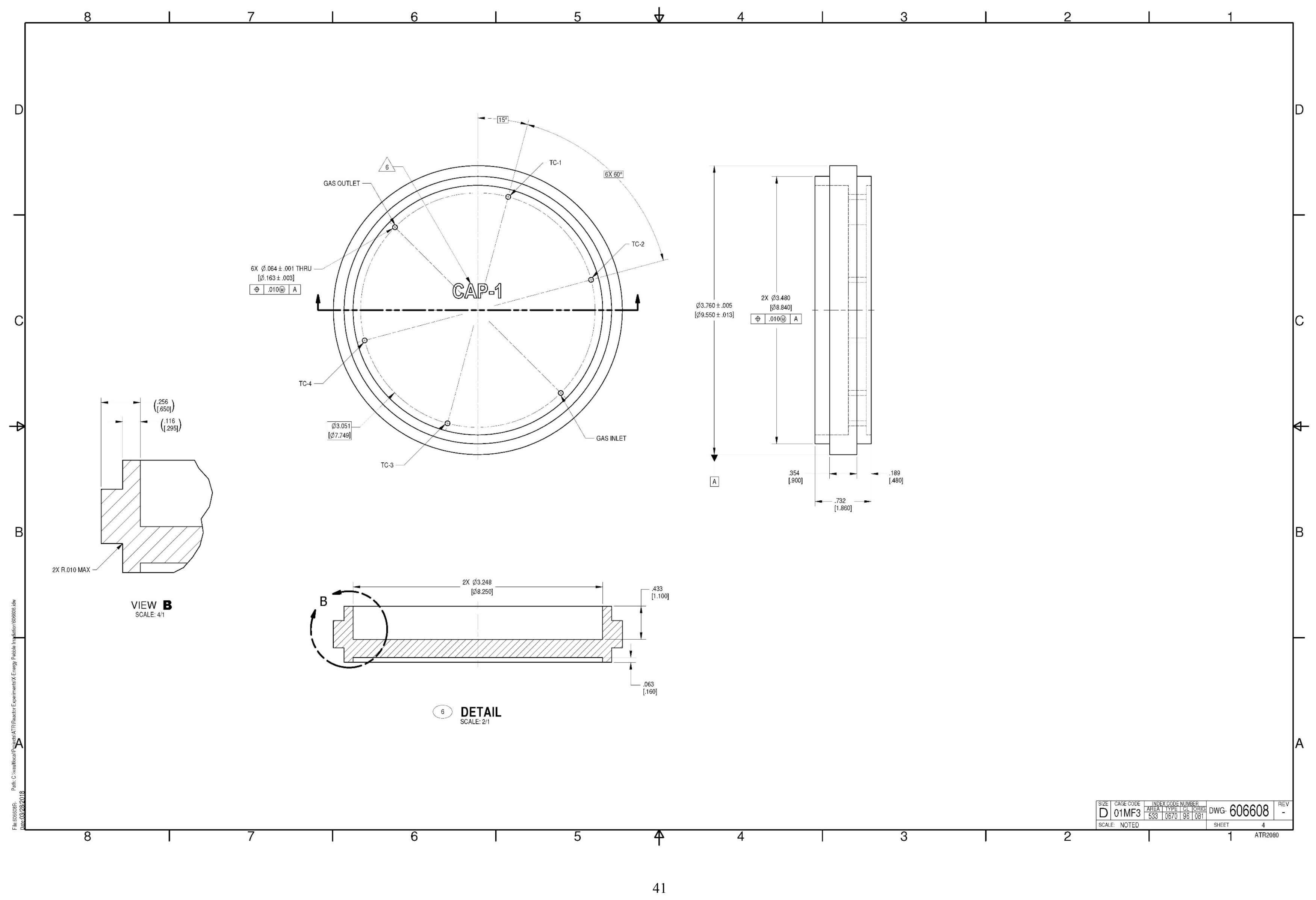




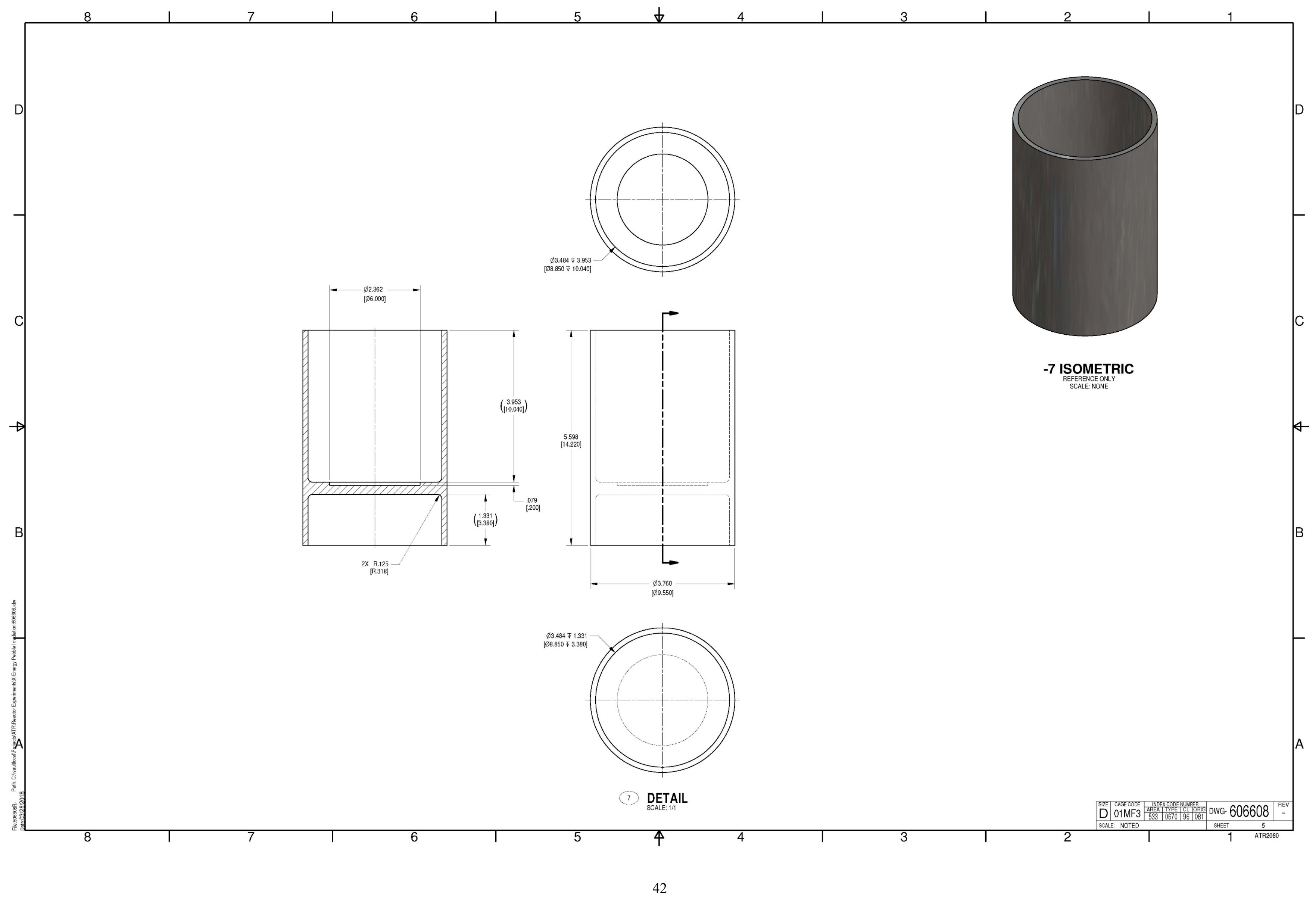




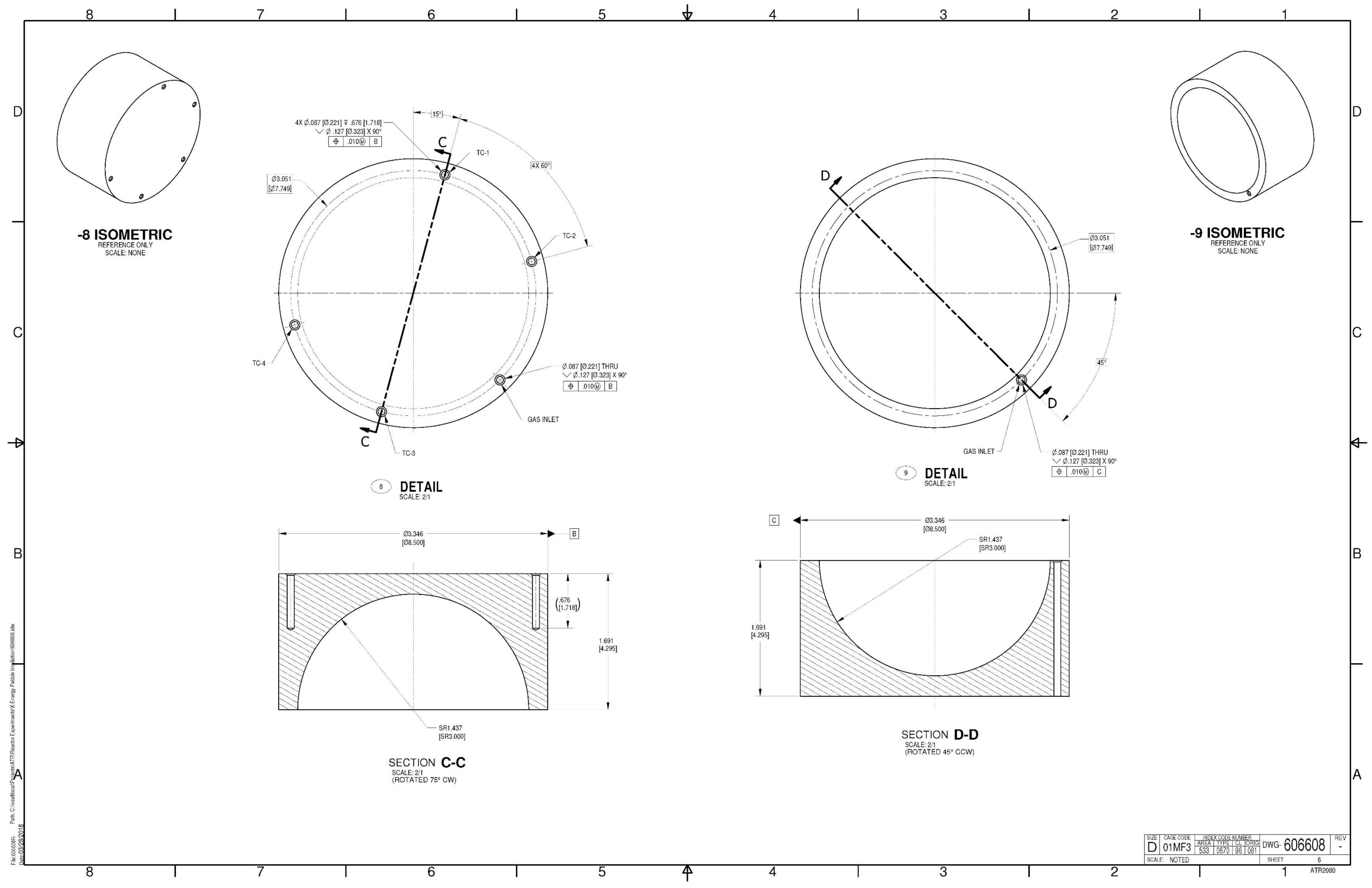




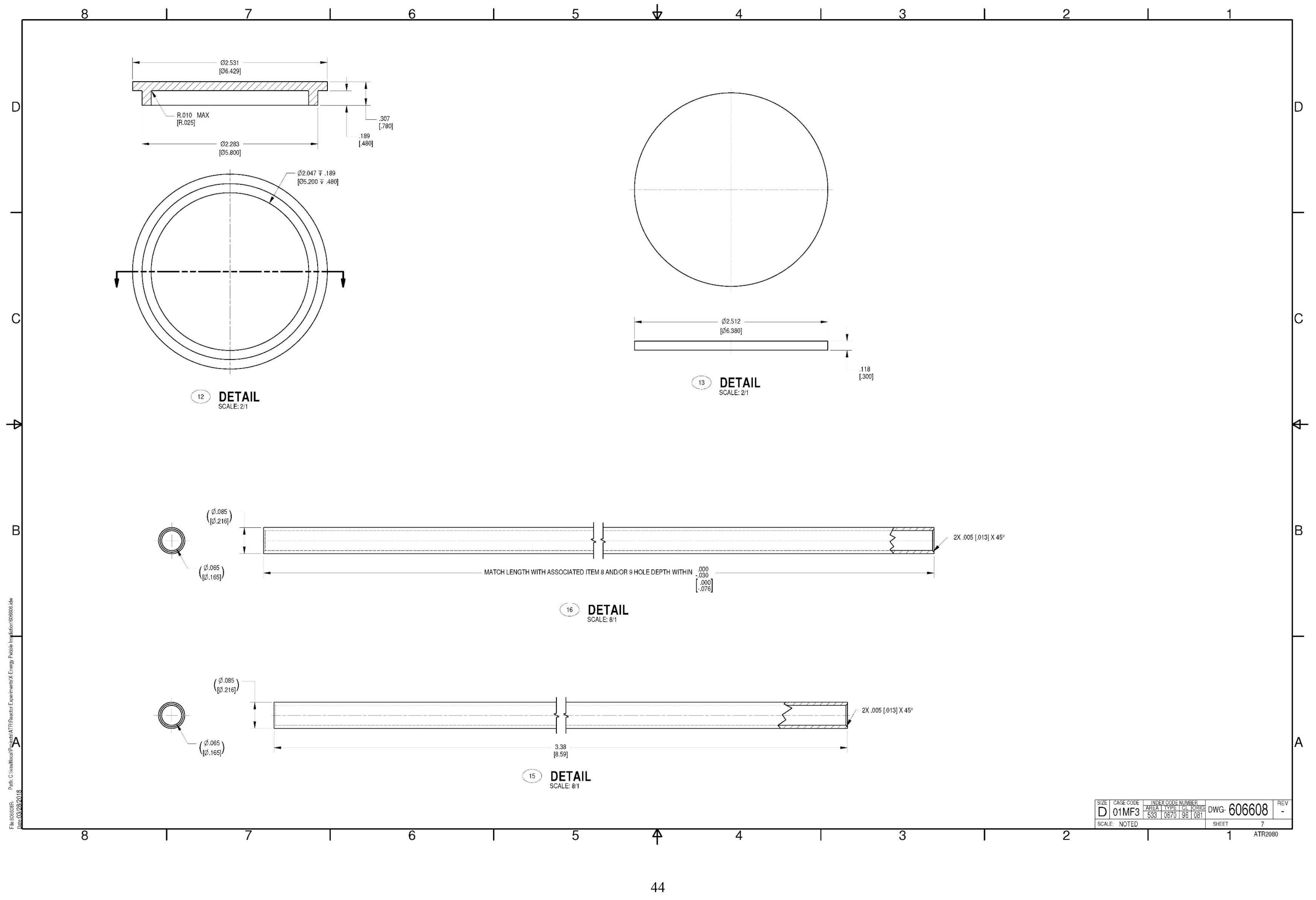




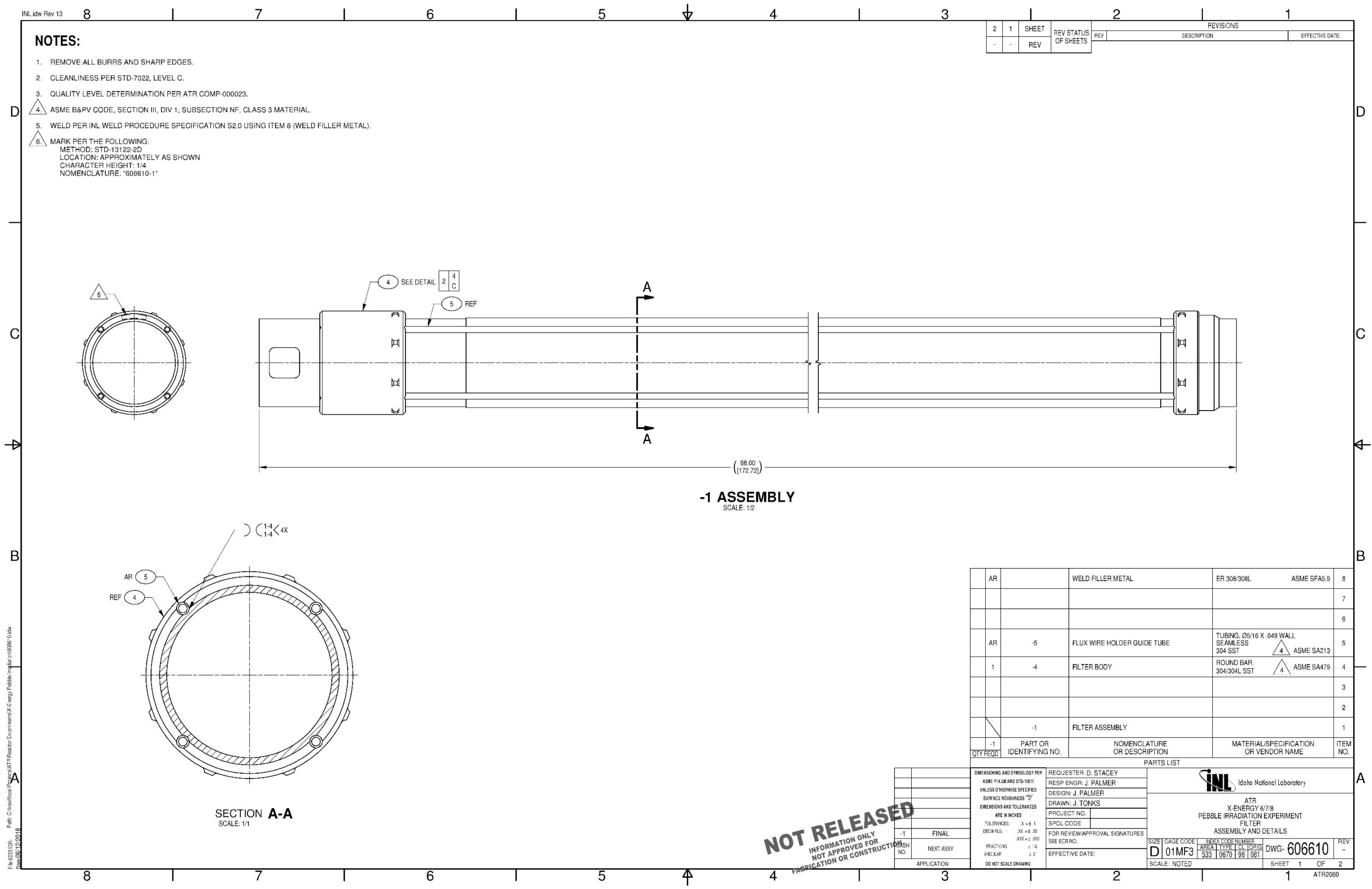




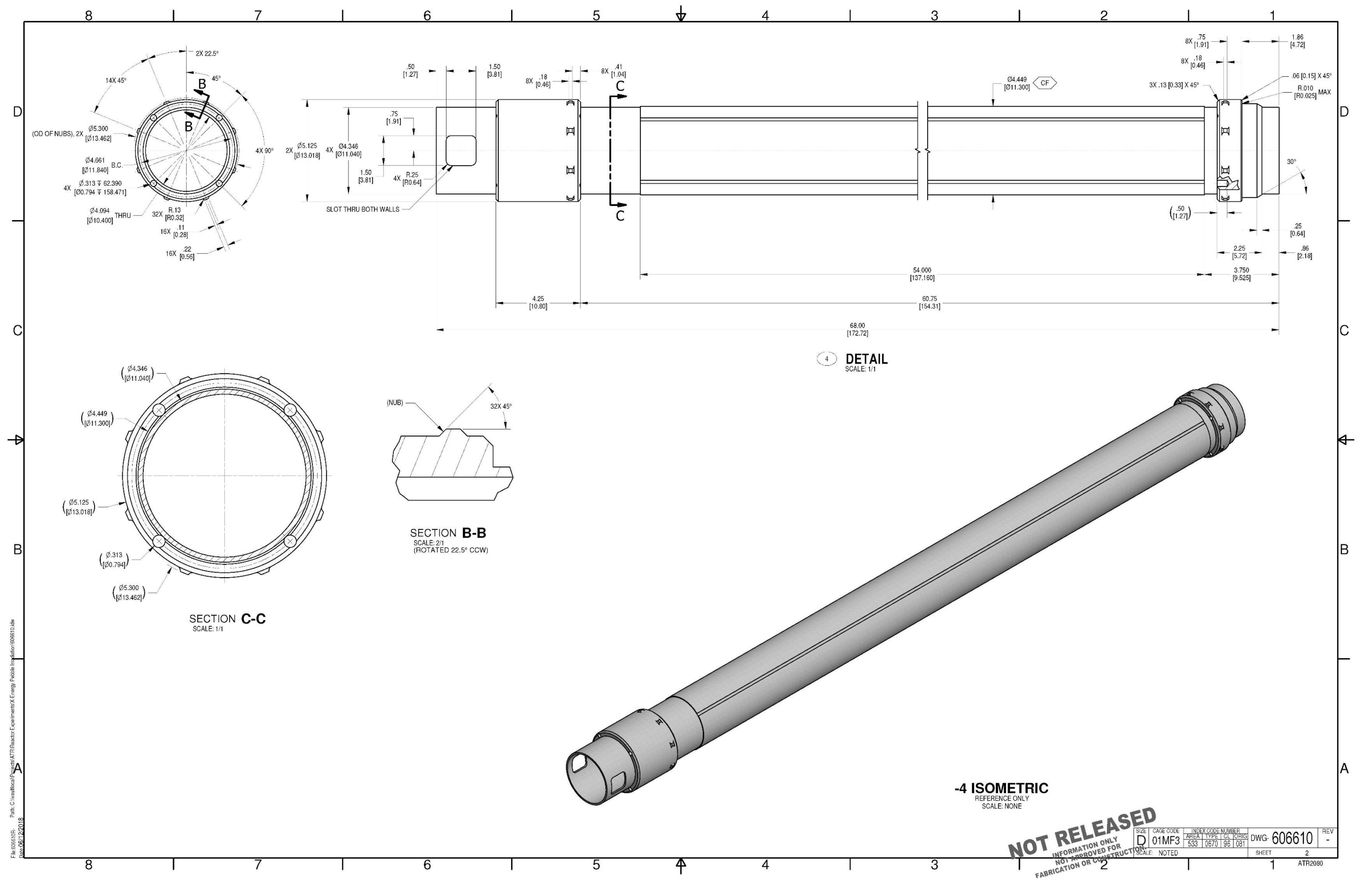

